


\title{
Cutthroat capitalism versus cuddly socialism: Are Americans more meritocratic and efficiency-seeking than Scandinavians?
}

\author{
Ingvild Almås \\ Alexander Cappelen \\ Bertil Tungodden*
}

\begin{abstract}
There is a striking difference in income inequality and redistributive policies between the United States and Scandinavia. To study whether there is a corresponding cross-country difference in social preferences, we conducted the first large-scale international social preference experiment, with nationally representative samples from the United States and Norway. We introduce a new experimental approach, which combines the infrastructure of an international online market place and the infrastructure of a leading international data collection agency. A novel feature of our experiment is that Americans and Norwegians make real distributive choices in identical situations where they have complete information about the source of inequality and the cost of redistribution. We show that Americans and Norwegians differ significantly in fairness views, but not in the importance assigned to efficiency. The study also provides robust causal evidence of fairness considerations being much more fundamental for inequality acceptance than efficiency considerations in both countries.
\end{abstract}

\footnotetext{
*Almås: IIES - Institute for International Economic Studies, Stockholm University and NHH Norwegian School of Economics; Cappelen and Tungodden: NHH Norwegian School of Economics. We are grateful to Björn Bartling, Roland Benabou, Lars Ivar Oppedal Berge, Gary Charness, Thomas Christiano, Pablo Branas-Garza, Daniel Chen, Yan Chen, Stefano DellaVigna, Thomas Dohmen, Ranveig Falch, Armin Falk, Marc Fleurbaey, Uri Gneezy, David Huffman, Alex Imas, Praveen Kujal, Ismael Rodriguez-Lara, Joshua Miller, Karl Ove Moene, Michael Norton, Axel Ockenfels, Torsten Persson, Charlotte Ringdal, Christopher Roth, Agnar Sandmo, Ingrid Hoem Sjursen, Vincent Somville, Sigve Tjøtta, Alain Trannoy, Lore Vandewalle, Lise Vesterlund, Martine Visser, Roberto Weber, and Kelly Zhang for great comments and suggestions and to Sebastian Fest and Ingar Haaland for excellent research assistance. The project was financed by support from the Research Council of Norway, research grant 236995 and administered by The Choice Lab. The experiment is registered in the Registry for Randomized Controlled Trials operated by the American Economic Association: RCT ID AEARCTR0000487.
} 


\section{Introduction}

An important question is how to understand the striking variation in income inequality and redistributive policies across the world (Piketty, Saez, and Stantcheva, 2014). The difference between the United States and the Scandinavian countries is a case in point. As shown in Figure 1, the United States is an outlier among the OECD countries with very high income inequality, while the Scandinavian countries are characterized by much more compressed income distributions. The same picture emerges if we compare these societies in terms of the top one percent earners in society: they capture almost $18-19 \%$ of total income in the United States, but only around 5-8\% in the Scandinavian countries (Atkinson, Piketty, and Saez, 2011). The United States and the Scandinavian countries also differ dramatically with respect to redistributive policies, with the Scandinavian countries having a significantly higher tax level and a more generous welfare state than the United States (Barth, Moene, and Willumsen, 2014).

[ Figure 1] about here]

These striking differences between the United States and Scandinavia have attracted the attention of economists and other social scientists (Aaberge, Björklund, Jäntti, Palme, Pedersen, Smith, and Wennemo, 2002; Aarøe and Petersen, 2014; Acemoglu, Robinson, and Verdier, 2012; Edlund, 1999; Fochesato and Bowles, 2015, Jantti, Bratsberg, Roed, Raaum, Naylor, Osterbacka, Bjorklund, and Eriksson, 2006, Kleven, 2014; Rogerson, 2007; Scruggs, Jahn, and Kuitto, 2014; Stiglitz, 2015) and have also been discussed extensively in the broader public debate (Booth, 2016; Irwin, 2014; Tassinari, 2013), where the comparison has sometimes been portrayed as being between cutthroat capitalism and cuddly socialism.

In this paper, we study whether these very different ways of organizing society correspond to differences in the social preferences of Americans and Scandinavians, in particular to differences in what kind of inequalities are considered fair and in the importance assigned to fairness relative to efficiency. By now, it is well established that social preferences fundamentally shape individual behavior (Andreoni and Miller. 2002; Bartling, Fehr, and Schmidt, 2012; Bartling, Weber, and Yao, 2015; Bolton and Ockenfels, 2000; Cappelen, Drange Hole, Sørensen, and Tungodden, 2007; Cappelen, Konow, Sørensen, and Tungodden, 2013a; Charness and Rabin, 2002; Falk and Szech, 2013; Fehr, Kirchsteiger, and Riedl, 1993; Fehr and Schmidt, 1999), and the prevalence of different social preferences in the United States and Scandinavia could therefore contribute to explain why these two societies have very different redistributive institutions: if Americans are more likely than Scandinavians to consider an inequality as fair and assign more weight to efficiency relative to fairness, then this may be one reason why there is more income inequality and less demand for redistribution in the United States than in Scandinavia.

There are, however, other potential explanations for why the Scandinavian countries are more equal and more redistributive than the United States. Importantly, it 
may be that Americans differ from Scandinavians in what they believe to be the source of income inequality in society. In particular, the United States and Scandinavia may be in different social equilibria with different self-sustained beliefs, where income inequality in the United States to a larger extent than in Scandinavia is believed to be the result of differences in individual productivity rather than luck (Alesina and Angeletos, 2005; Bénabou and Tirole, 2006; Piketty, 1995). These different social equilibria are consistent with Americans and Scandinavians having the same meritocratic fairness view, considering inequalities due to differences in individual productivity as fair and inequalities due to differences in luck as unfair. In short, it may be that Americans accept more inequality and are less in favor of redistribution than Scandinavians because they have different beliefs about the source of inequality in society.

Another possibility is that beliefs about the cost of redistribution differ significantly between the United States and Scandinavia. For example, it has been argued that the Scandinavian countries represent a role model for how to run an efficient and responsive state (The Economist, February 2, 2013), and it may be that Americans are less in favor of redistribution than Scandinavians because they have less trust in the government implementing redistributive schemes in an efficient manner (Kuziemko, Norton, Saez, and Stantcheva, 2015). It has also been argued that since the United States is the vehicle of innovation and economic growth in the world, it would be much more costly for the United States than for the Scandinavian countries to implement comprehensive social welfare systems (Acemoglu et al., 2012), 1 In short, it may be that Americans accept more inequality and are less in favor of redistribution than Scandinavians because the cost of redistribution is (or is believed to be) greater in the United States than in Scandinavia.

These alternative explanations highlight the difficulty of inferring social preferences from actual levels of inequality and redistribution in the United States and Scandinavia: it may be that Americans face a very different distributive situation than Scandinavians, both with respect to the source of inequality and the cost of redistribution. In order to overcome this challenge when comparing the social preferences of Americans and Scandinavians, we conducted the first large-scale economic experiment where nationally representative samples of participants from the United States and from a Scandinavian country, Norway, made real distributive choices in identical distributive situations. ${ }^{2}$ By observing the distributive choices of Americans and Norwegians in identical distributive situations, where they had complete information about the source

\footnotetext{
${ }^{1}$ The fact that Scandinavia is much more homogenous and smaller than the United States may also contribute to make it easier to redistribute in Scandinavia than in the United States (Alesina and Giuliano, 2011). There are also other possible explanations for why Scandinavia has more redistribution than the United States, including differences in the political systems (Austen-Smith, 2000), different religious structures (Chen and Lind, 2015), and the difference in the role played by labor unions (Moene and Wallerstein, 1997).

${ }^{2}$ Norway is very similar to the two other Scandinavian countries, Denmark and Sweden, in economic organization and culture, and thus we do not expect there to be major differences in social preferences across Scandinavia.
} 
of inequality and the cost of redistribution, we identify whether the two populations differ in their social preferences.

Our study uses a novel empirical approach for collecting experimental data on nationally representative samples, by combining the infrastructure of an international online labor market platform and the infrastructure of a leading international data- collection agency. On the online market platform, we recruited individuals (workers) to conduct some assignments, and then recruited representative samples of individuals (spectators) from the United States and Norway through the international data collection agency, 1000 spectators from each country. The spectator's task was to decide whether to redistribute income between a pair of workers who had been allocated unequal earnings.

For each country, the spectators were randomly assigned to one of three treatments (luck treatment, merit treatment, and efficiency treatment), where the treatments only differed with respect to the source of the inequality in earnings or in the cost of redistribution. In the luck treatment, earnings were determined by luck and there was no cost of redistribution. In two additional treatments, we manipulated the source of inequality and the cost of redistribution, respectively. In the merit treatment, earnings were determined by individual productivity with no cost of redistribution; in the efficiency treatment, earnings were determined by luck but there was a cost of redistributing income from one worker to the other ${ }^{3}$ This design allows us to study whether there are systematic differences in what Americans and Scandinavians consider a fair inequality (by comparing the distributive choices in the luck treatment and the merit treatment) and in the weight attached to fairness relative to efficiency (by comparing the distributive choices in the luck treatment and the efficiency treatment). The experimental design also provides us with causal evidence of the importance of the source of inequality and the cost of redistribution for inequality acceptance. A pre-analysis plan, describing the main hypotheses to be tested and the identification strategy, was posted on the AEA RCT registry.

The study establishes that there are important differences in the prevailing social preferences between the United States and Norway. First, we find that Americans accept significantly more inequality than Norwegians, even when they make distributive choices in identical situations. On average, the Americans and the Norwegians implement an income distribution corresponding to an income inequality Gini of 0.43 (the United States) and 0.24 (Norway), a difference that is strikingly similar to the difference in the actual income inequality Gini between the two countries, see Figure 1. Second, we find that this difference in the level of inequality acceptance reflects a difference in fairness views, not a difference in the importance Americans and Norwegians assign to fairness relative to efficiency. A significantly larger share of the Americans choose according to a libertarian fairness view (which considers both in-

\footnotetext{
${ }^{3} \mathrm{We}$ did not include a treatment combining a difference in productivity as the source of inequality and a cost of redistribution, since we did not expect this to give qualitatively different results than the present efficiency treatment.
} 
equalities due to luck and inequalities due to a difference in productivity as fair), while a significantly larger share of the Norwegians choose according to an egalitarian fairness view (which considers all inequalities unfair). Interestingly, however, we do not find that Americans are more meritocratic than Norwegians, the share of spectators choosing according to a meritocratic fairness view (which only considers inequalities due to a difference in productivity as fair) is almost the same in the two countries.

The analysis shows that there are important heterogeneities in the social preferences within each country, where we focus on the subgroups that were specified in the pre-analysis plan (political orientation, socioeconomic background, and gender). In both the United States and Norway, we find that conservatives are more inequality accepting than non-conservatives; in all three treatments, conservative spectators implement significantly more inequality than non-conservative spectators. Interestingly, however, the within-country political difference in inequality acceptance in both countries is significantly smaller than the between-country difference in inequality acceptance. Further, we observe that the socioeconomic gradient plays a major role in the United States, where high education spectators are significantly more meritocratic than low education spectators. In contrast, there is no significant association between socioeconomic background and fairness views in Norway. Finally, we find that males accept more inequality than females, particularly in the United States.

The study also provides some important general insights into the nature of social preferences. First, we provide causal evidence suggesting that fairness considerations are much more fundamental for inequality acceptance than efficiency considerations. In both countries, the introduction of a productivity difference instead of luck as the source of inequality causes a huge increase in inequality acceptance, while the introduction of a cost of redistribution has a negligible effect on spectator choices. In fact, we find a highly significant merit treatment effect in all pre-specified subgroups in both countries, while we only find a significant efficiency treatment effect among conservatives and male spectators in Norway. Second, we find that the meritocratic fairness view is most prevalent in both countries; we estimate that 37.5 percent (the United States) and 42.5 percent (Norway) of the spectators consider inequalities due to a difference in productivity as fair and inequalities due to luck as unfair. We do, however, also observe within-country heterogeneity in fairness views; there are significant shares of egalitarians and libertarians in both countries. Overall, our estimates suggest that the vast majority of the spectators ( 87 percent) can be characterized as having an egalitarian, meritocratic, or libertarian fairness view.

The paper contributes to the large literature on international differences in attitudes towards inequality and redistribution. One strand of this literature has relied on large, non-incentivized representative surveys, including the World Value Survey, the European Social Survey, the General Social Survey, and the International Social Survey Programme (Alesina, Glaeser, and Sacerdote, 2001; Alesina and Glaeser, 2004; Alesina and Giuliano, 2011; Aarøe and Petersen, 2014; Ashok, Kuzimko, and Washington, 2015; Corneo and Grüner, 2002; Edlund, 1999; Falk, Becker, Dohmen, Enke, Huffman, and Sunde, 2015; Fong, 2001; Kiatpongsan and Norton, 2014; Linos and 
West, 2003; Luttmer and Singhal, 2011; Osberg and Smeeding, 2006; Svallfors, 1997), while another strand has used incentivized lab-experiments on non-representative samples (Barrett, Bolyanatz, Crittenden, Fessler, Fitzpatrick, Gurven, Henrich, Kanovsky, Kushnick, Pisor, Scelza, Stich, von Rueden, Zhaog, and Laurence, 2016; Cappelen, Nygaard, Sørensen, and Tungodden, 2015; Farina, Grimalda, and Schmidt, 2016, Henrich, Boyd, Bowles, Camerer, Fehr, Gintis, McElreath, Alvard, Barr, Ensminger, Henrich, Hill, Gil-White, Gurven, Marlowe, Patton, and Tracer, 2005; Henrich, Ensminger, McElreath, Barr, Barrett, Bolyanatz, Cardenas, Gurven, Gwako, Henrich, Lesorogol, Marlowe, Tracer, and Ziker, 2010; Jakiela, 2015). We propose a new empirical approach for these types of studies that combines the strengths of the survey approach (large representative samples) and the lab experimental approach (incentivized choices). By combining the infrastructure of an international online labor market platform and the infrastructure of a leading international data collection agency, we are able to collect data on how large representative samples make distributive choices in real situations.

An important contribution of the previous literature has been to provide survey evidence showing that the support for redistribution depends on beliefs about the sources of income inequality (Aarøe and Petersen, 2014; Alesina et al., 2001; Fong, 2001; Linos and West, 2003): people who believe that prosperity is a result of hard work and good choices are less willing to redistribute than people who believe that prosperity is caused by luck. Our study, however, focuses on identifying the fairness preferences of individuals, by studying how they make choices in distributive situations where we can control the beliefs about the source of inequality. We show that Americans and Norwegians do not only differ in their beliefs, they also fundamentally differ in terms of fairness preferences.

The paper also contributes to the large experimental literature on the nature of social preferences (Andreoni and Miller, 2002; Andreoni, Aydın, Barton, Bernheim, and Naecker, 2016; Bellemare, Kröger, and van Soest, 2008; Cappelen et al., 2007; Cappelen, Sørensen, and Tungodden, 2010; Cappelen et al., 2013a; Charness and Rabin, 2002; Engelmann and Strobel, 2006; Fehr, Naef, and Schmidt, 2006; Fehr, Bernhard, and Rockenbach, 2008; Fehr, Glätzle-Rützler, and Sutter, 2013, Konow, 1996, 2000; Smeets, Bauer, and Gneezy, 2015), in particular by studying the importance of the source of inequality and the cost of redistribution for inequality acceptance in large nationally representative samples. We show that the source of inequality is essential for understanding inequality acceptance in both the United States and Norway; in all subgroups of our samples, we find that the introduction of a difference in productivity as the source of inequality significantly increases inequality acceptance. We also show that fairness considerations appear to be much more important for individuals than efficiency considerations. We believe that these insights shed important light on the nature of social preferences and what drives attitudes towards redistribution in society.

The paper is organized as follows: Section 2 describes the experimental design, Section 3 introduces a simple theoretical framework that guides our interpretation of the results, Section 4 outlines the empirical strategy, Section 5 reports the main results 
and the heterogeneity analysis, while Section 6 concludes.

\section{Experimental Design and Participants}

We first provide an overview of the general structure of the experiment, and then a detailed discussion of the participants and the treatments. The experiment had two types of participants, workers and spectators. The spectators decided whether or not to redistribute earnings between a pair of workers who had completed the same assignment. The spectators were randomly assigned to one of three treatments that only differed with respect to the source of inequality in earnings or the cost of redistribution. Table 1 summarizes the main stages in the experiment.

[ Table 1 about here]

At the end of the experiment, the spectators completed a non-incentivized survey that included a question about their attitude towards redistributive policies as well as standard background questions about gender, age, geographical location, household income, political orientation, and education.

\subsection{The workers}

The workers in the experiment were recruited from the international online labor market platform Amazon Mechanical Turk, which is a crowdsourcing web service that specializes in recruiting anonymous workers to complete small tasks online. When recruited, the workers were promised a participation fee of 2 USD and told that they could earn additional money, depending on the actions they and others would take in the experiment ${ }^{4}$

We recruited 1334 workers and each worker completed three different assignments. After they had completed all three assignments, the workers were told that they would be paid for the assignments. Specifically, for each assignment, they were randomly matched in pairs, giving us 2001 unique pairs of assignments/workers. In each pair, one worker was initially assigned 6 USD and the other 0 USD for completing the task. The workers were told how the initial assignment of earnings would be determined, but not whether they had been assigned high or no initial earnings. They were told, however, that a third person, the spectator, would be informed about the assignment and the initial distribution of earnings, and would be given the opportunity to redistribute the earnings between the two workers in the pair and thus determine how much they were actually paid for the assignment. The workers received the income determined by the spectator within a few days after the spectators made their choice.

\footnotetext{
${ }^{4}$ The complete instructions for both workers and spectators are provided in Appendix B.
} 


\subsection{The spectators}

The spectators in the experiment were recruited by using the infrastructure of the data collection agency Norstat and its collaborator in the United States, Research Now. In both countries, we recruited 1000 participants who constitute a nationally representative sample $(+18$ years old) on observable characteristics (age, gender, and geography). Table 2 provides an overview of the background characteristics of the spectators in the United States and in Norway. We observe that the income distribution is much more compressed in Norway than in the United States, but otherwise the distributions of the different background characteristics are relatively similar in the two countries.

[ Table 2]about here]

The spectators were randomly assigned to one of three treatments. Each spectator was matched with a unique pair of workers and decided whether and how much of the initial earnings to redistribute 5 It was emphasised to the spectators that, in contrast to traditional survey questions, their choice would have consequences for a real life situation. They were fully informed about the information that had been provided to the workers. Importantly, the experimental design ensured that the spectators in the United States and the spectators in Norway faced identical distributive situations and were given the exact same information about the source of inequality and the cost of redistribution. Some features of the information given to the spectators are important for the interpretation of our result. First, the spectators were informed that we had not announced the payment to the workers in advance, which removed the possibility that spectators held different beliefs about the choice of effort across treatments. Second, the spectators were informed that the workers would not at any point be informed about their initial earnings, which we did in order to minimize the role of worker expectations in the spectator choice. Third, the spectators had no information about the nationality of the workers, and thus there is no reason to expect that the Americans or the Norwegians felt closer to the workers. Overall, the aim was to have an experimental design that allowed us to compare social preferences between the United States and Norway as cleanly as possible, and to identify the importance of the source of inequality and the cost of redistribution for inequality acceptance.

\subsection{The treatments}

In all treatments, the initial distribution of earnings was the same (6 USD, 0 USD), i.e., one worker had earned all the money and the other worker had earned nothing. The task of the spectators was to determine whether to redistribute some of the initial earnings from the worker with 6 USD to the worker with 0 USD, where the treatments only differed with respect to the source of the inequality in earnings or the cost of

\footnotetext{
${ }^{5}$ One spectator decision was applied twice, since we had 2001 unique distributive situations and 2000 spectators.
} 
redistribution in the distributive situation. We now provide a detailed discussion of each treatment, referred to as the luck, merit, and efficiency treatments.

In the luck treatment, which in the following analysis will serve as the base treatment, the spectators were informed that the initial earnings for the assignment had been determined by a lottery. The worker winning the lottery had been assigned 6 USD and the other worker had been assigned 0 USD. The spectators were also explained that the workers had not been informed about the outcome of the lottery, but had only been told that a third person, the spectator, would be informed and would be given the opportunity to redistribute the initial earnings. The spectators could choose not to redistribute, i.e. choose the income distribution $(6,0)$, or to redistribute and choose one of the following income distributions: $(5,1),(4,2),(3,3),(2,4),(1,5)$ or $(0,6)$. In the luck treatment, there was no cost of redistribution, so that the total income to the two workers would always be 6 USD.

In the merit and efficiency treatments, we manipulated the source of inequality and the cost of redistribution, respectively $]^{6}$ In the merit treatment, the initial assignment of earnings was determined by the productivity of the workers. The more productive worker in the pair was assigned 6 USD, whereas the less productive worker was assigned 0 USD $]^{7}$ The source of inequality in the initial assignment of earnings was thus a difference in productivity rather than luck. In all other respects, the merit treatment was identical to the luck treatment. In particular, the workers had not been informed about the initial assignment of earnings and there was no cost of redistribution.

The efficiency treatment only differed from the luck treatment with respect to the cost of redistribution, which was equal to $100 \%$ of the transferred amount: for each dollar redistributed, the income to the lucky worker with earnings would be reduced by two dollars 8 The spectator thus could choose not to redistribute, i.e. keep the income distribution $(6,0)$, or to redistribute and choose one of the following income distributions: $(4,1),(2,2),(0,3)$.

The three treatments can be summarized as follows:

- Luck treatment $(L)$ : The spectator chooses payments in a distributive situation where luck is the source of inequality and there is no cost of redistribution.

- Merit treatment $(M)$ : The spectator chooses payments in a distributive situation

\footnotetext{
${ }^{6}$ The workers completed two sentence unscrambling tasks and a code recognition task. We only measured performance in the code recognition task, which was then used for the merit treatment. In the two other treatments, we used the sentence unscrambling task. The nature of the task was not revealed to the spectators.

${ }^{7}$ We chose this design for two reasons. First, it captures an interesting set of situations, where the more productive worker takes all the surplus. Second, it simplified the information we had to share with the participants, which was an important consideration given that we worked with a nationally representative sample. The spectators were not given any information about how much the two workers differed in their production.

${ }^{8}$ Our design thus implements the cost of redistribution in terms of an iceberg transport cost (Samuelson, 1954).
} 
where a difference in productivity is the source of inequality and there is no cost of redistribution.

- Efficiency treatment $(E)$ : The spectator chooses payments in a distributive situation where luck is the source of inequality and there is a significant cost of redistribution.

By comparing the distributive behavior of the spectators in the luck treatment and the merit treatment, we are able to identify the causal effect of varying the source of inequality (luck versus a difference in productivity) on the level of redistribution. Correspondingly, by comparing the distributive behavior of the spectators in the luck treatment and the efficiency treatment, we are able to identify the causal effect of introducing a significant cost of redistribution.

The treatments are also illuminating for the comparison between the United States and Norway. By comparing the merit treatment effect for the American spectators with the merit treatment effect for the Norwegian spectators, we can test whether the Americans are more meritocratic than the Norwegians. And by comparing the efficiency treatment effect for the American spectators with the efficiency treatment effect for the Norwegian spectators, we can test whether the Americans are more efficiency-seeking than the Norwegians.

\section{Theoretical framework}

We here provide a simple social preference model to guide our analysis and the interpretation of the results, extending the spectator framework introduced in Cappelen et al. (2013a).

The spectator is informed about initial earnings and then decides on a distribution $(1-y, y)$ in treatment $j=L, M, E$, where $y$ is the share of total income to the worker with no pre-redistribution earnings. We assume that the spectator cares about fairness and efficiency, as captured by the following utility function:

$$
V(y ; \cdot)=-\frac{\beta}{2}(y-m(j))^{2}-c(j) y,
$$

where $\beta \geq 0$ is the weight attached to fairness relative to efficiency, $m(j)$ is what the spectator considers to be the fair share to the worker with no pre-redistribution earnings in treatment $j$, and $c(j) \geq 0$ is the cost of redistribution in treatment $j:^{9}$

The model captures that the social preferences of the spectators may differ in two respects: in what they consider a fair distribution of income, $m(\cdot)$, and in the importance they attach to fairness relative to efficiency, $\beta$. The optimal interior solution is given by:

\footnotetext{
${ }^{9}$ This formulation of the utility function assumes that the fair share is independent of the size of the total income. The assumption is only binding in the efficiency treatment, where the cost of redistribution implies that total income may differ from total earnings.
} 


$$
y(j)=m(j)-\frac{c(j)}{\beta} .
$$

It follows straightforwardly that if there is no cost of redistribution, then the spectator implements the fair solution, i.e. $y(j)=m(j)$. When there is a cost of redistribution, the spectator makes a tradeoff between fairness considerations and efficiency considerations. A spectator prefers to give nothing to the worker with no pre-redistribution earnings when $\beta \leq \frac{c}{m}$. A spectator who mainly cares about fairness assigns a share close to what he or she considers the fair distribution, i.e. $\beta \mapsto \infty$ implies that $y \mapsto m$.

We can now illustrate how the treatment comparisons in the experiment can be used to study the two dimensions of the spectator's social preferences captured by this model: the fairness view and the weight attached to fairness. It follows straightforwardly from the model that if there is a difference between the merit treatment and the luck treatment in the share given to the worker with no initial earnings, then this identifies that the source of inequality matters for the spectator's fairness view:

$$
\text { Merit versus Luck: } \quad y(L)-y(M)=m(L)-m(M) .
$$

To study the weight attached to fairness relative to efficiency, we introduce the assumption that a cost of redistribution does not affect what the spectator views to be fair to give to the worker with no initial earnings, i.e., $m(L)=m(E){ }^{10}$ It now follows from the model that any difference between the luck treatment and the efficiency treatment is driven by the cost of redistribution and the weight attached to fairness:

$$
\text { Efficiency versus Luck: } y(L)-y(E)=\frac{c(E)}{\beta} .
$$

In the analysis, we also study the prevalence of specific fairness views among the spectators, where we focus on the most salient fairness views in this type of distributive situations (Cappelen et al., 2007, Almås, Cappelen, Sørensen, and Tungodden, 2010, Cappelen et al., 2013a): ${ }^{11}$

- Egalitarian fairness view: It is fair that the workers receive the same income independent of their earnings, i.e., $m(L)=m(M)=m(E)=1 / 2$.

\footnotetext{
${ }^{10}$ This assumption captures that fairness relates to the source of inequality, which is luck in both treatments, and is necessary in order to distinguish between fairness and efficiency considerations in the analysis.

${ }^{11}$ There is a rich literature in political philosophy and economics on how to understand these fairness views, see for example Arrow, Bowles, and Durlauf (2000); Brennan, van der Vossen, and Schmidtz (2016). Our definitions only intend to capture features of these fairness views that are of relevance for the present study. In particular, our definition of libertarianism is an interpretation of the libertarian principle of non-interference, which is a central feature of libertarian theories of fairness and underlies the classical justification of a minimal state (Nozick, 1974).
} 
- Meritocratic fairness view: It is fair that the more productive worker receives a higher income than the less productive worker, but income inequalities due to luck are not fair, i.e., $m(M)<1 / 2$ and $m(L)=m(E)=1 / 2$.

- Libertarian fairness view: It is fair that the income of the workers is equal to their earnings, i.e., $m(L)=m(M)=m(E)=0$.

The egalitarian fairness view considers it fair to divide equally in both the merit and the luck treatment, while the libertarian fairness view considers it fair that the workers receive their earnings in all treatments. Only the meritocratic fairness view assigns importance to the source of inequality, where inequality due to luck is considered unfair while inequality due to merit is considered fair.

A difference in behavior between the merit and luck treatments has to be driven by the spectators with a meritocratic fairness ideal, while a difference in behavior between the luck treatment and the efficiency treatment has to be driven by the meritocratic and the egalitarian spectators. Spectators with a libertarian fairness view do not face a tradeoff between fairness considerations and efficiency considerations in the efficiency treatment, since for them the fair and efficient distribution coincide ${ }^{12}$ Hence, the effect of introducing a cost of redistribution depends both on how many of the spectators that are non-libertarian and on the relative importance these spectators assign to efficiency.

The theoretical framework is illuminating for the comparison of the social preferences of Americans and Norwegians. First, it follows from (3) that a country difference in the merit treatment effect reflects that Americans and Norwegians differ in their fairness view. In particular, if there are more meritocrats in the United States than in Norway, then the model predicts a greater merit treatment effect for the American spectator than for the Norwegian spectators. Second, it follows from (4) that if the spectators are at interior solutions, a country difference in the efficiency treatment effect reflects a difference between Americans and Norwegians in the weight they attach to fairness. In particular, if Americans assign less weight to fairness relative to efficiency than do Norwegians, then the model predicts a greater efficiency treatment effect in the United States than in Norway. However, the two countries may also differ in the share of spectators who actually make a tradeoff between fairness and efficiency. Specifically, if there are more libertarians in the United States than in Norway, then the model predicts a smaller efficiency treatment effect in the United States than in Norway.

\section{Empirical strategy}

The empirical strategy was specified in a pre-analysis plan that was registered at the AER RCT Registry before we analyzed the data, and included pre-specification of the

\footnotetext{
${ }^{12}$ Note that this coincidence is inherent to the libertarian fairness view and not a feature of our specific experimental design, since the libertarian fairness view would consider any pre-redistribution distribution of income between the two workers as fair.
} 
different hypotheses to be tested, of the regression approach, and of the dimensions to be studied in the heterogeneity analysis. ${ }^{13}$

\subsection{Main analysis}

Our main variable of interest is the inequality implemented by spectator $i$, which is measured as follows:

$$
e_{i}=\frac{\mid \text { Income Worker } A_{i}-\text { Income Worker } B_{i} \mid}{\text { Total Income }}=\left|1-2 y_{i}\right| \in[0,1],
$$

where Worker $A_{i}$ is the worker with high pre-redistribution earnings. This inequality measure is equivalent to the Gini-coefficient in the two-person-situations considered by the spectators. The pre-redistribution income inequality is equal to one in all the distributive situations in the experiment, and it is equal to zero if the spectator decides to completely equalize the incomes of the two workers.

The main empirical specification used in the analysis is:

$$
e_{i}=\alpha+\alpha_{M} M_{i}+\alpha_{C} C_{i}+\delta N_{i}+\delta_{M} M_{i} N_{i}+\delta_{C} C_{i} N_{i}+\gamma \mathbf{X}_{i}+\varepsilon_{i},
$$

where $e_{i}$ is the income inequality implemented by spectator $i, M_{i}$ and $C_{i}$ are indicator variables for spectator $i$ being in the merit or efficiency treatment, $N_{i}$ is an indicator variable for spectator $i$ being from Norway, $M_{i} N_{i}$ and $C_{i} N_{i}$ are interactions between treatment indicator variables and country indicator variables, and $\mathbf{X}_{i}$ is a vector of control variables. Although our main specification includes the control variables, we also report and discuss results for regressions without control variables.

The luck treatment is the reference category in (6), and the estimates are therefore to be interpreted relative to a baseline situation where luck is the source of inequality and there is no cost of redistribution ${ }^{14}$ From equation (6), we obtain estimates of the causal effects of varying the source of inequality and the cost of redistribution on inequality acceptance:

- The estimated causal effect on inequality acceptance of a difference in productivity being the source of inequality is given by $\alpha_{M}$ (United States) and $\alpha_{M}+\delta_{M}$ (Norway), and the estimated country difference in the causal effect of introducing a difference in productivity is given by $\delta_{M}$.

- The estimated causal effect on inequality acceptance of a cost of redistribution is given by $\alpha_{C}$ (United States) and $\alpha_{C}+\delta_{C}$ (Norway), and the estimated country difference in the causal effect of introducing a cost of redistribution is given by $\delta_{C}$.

\footnotetext{
${ }^{13} \mathrm{https}: / /$ www.socialscienceregistry.org/trials/487/history/2506.

${ }^{14} \mathrm{We}$ pre-specified one-sided tests of the causal effects of introducing a difference in productivity and a cost of redistribution on inequality acceptance, since there is no reason to believe that merit and efficiency considerations should cause reduced inequality acceptance. In the analysis, however, we report the two-sided tests, since it is straightforward to derive the implications from one-sided tests.
} 
Equation (6) also provides the foundation for a test of whether there is systematically more inequality acceptance in one of the countries, which we defined in the pre-analysis plan to be the case if the spectators in one of the countries implemented more inequality in all three treatments. To illustrate, we consider there to be systematically more inequality acceptance in the United States than in Norway if the Norwegians implemented less inequality in the luck treatment $(\delta<0)$, the merit treatment $\left(\delta+\delta_{M}<0\right)$, and the efficiency treatment $\left(\delta+\delta_{C}<0\right)$.

We also provide estimates of the prevalence of the different fairness views in the two countries. This part of the analysis was not specified in the pre-analysis plan, but builds on our previous work on fairness preferences (Cappelen et al., 2007; Almås et al., 2010, Cappelen, Moene, Sørensen, and Tungodden, 2013b). We focus on estimating the shares of egalitarians, libertarians, and meritocrats in the sample, where we rely on the behavior in the merit treatment and the luck treatment. The prevalence of each of the three fairness views is estimated in the following way:

- Egalitarians: The share of egalitarians is given by the share of spectators dividing equally in the merit treatment.

- Meritocrats: The share of meritocrats is given by the difference between the share of spectators allocating more to the more productive worker in the merit treatment and the share of spectators allocating more to the lucky worker in the luck treatment.

- Libertarians: The share of libertarians is given by the share of spectators allocating everything to the lucky worker in the luck treatment.

The share of spectators who are not classified by this procedure is referred to as having Other fairness views 15

Finally, we analyze whether there is an association between the level of inequality implemented by a spectator in the experiment and his or her attitude towards redistribution in society. In the survey, we asked the spectators to indicate the extent to which they agree that society should aim to equalize incomes $(1-10 ; 1$ : completely agree, 10 : completely disagree), and we study whether spectators more in agreement with society equalizing incomes implement less inequality in the experiment. We provide a discussion of the main finding of this analysis in the paper, while the detailed regression analysis is reported in Appendix A.

\subsection{Heterogeneity and robustness analysis}

We study heterogeneity in social preferences in the United States and Norway using the background data collected in the survey, where, as pre-specified, we focus on political orientation, socioeconomic status, and gender. Specifically, we test whether there are

\footnotetext{
${ }^{15}$ In Appendix A, we provide a further discussion of our estimation of fairness types.
} 
differences in social preferences between conservatives and non-conservatives, high and low socioeconomic status individuals (education), and males and females 16

The heterogeneity analysis is conducted by estimating the following regression for each of the three background variables:

$$
\begin{aligned}
e_{i}=\alpha & +\alpha^{B} B_{i}+\alpha_{M} M_{i}+\alpha_{M}^{B} M_{i} B_{i}+\alpha_{C} C_{i}+\alpha_{C}^{B} C_{i} B_{i} \\
& +\delta N_{i}+\delta^{B} B_{i} N_{i}+\delta_{M} M_{i} N_{i}+\delta_{M}^{B} M_{i} B_{i} N_{i}+\delta_{C} C_{i} N_{i}+\delta_{C}^{B} C_{i} B_{i} N_{i}+\gamma \mathbf{X}_{i}+\varepsilon_{i},
\end{aligned}
$$

where $B_{i}$ is an indicator variable for spectator $i$ being either conservative, having high education, or being female. 17 In addition to the variables included in (6), this regression also includes interactions between the background indicator variable and the treatment indicator variable, $M_{i} B_{i}$ and $C_{i} B_{i}$, an interaction between the background indicator variable and the country indicator variable, $B_{i} N_{i}$, and triple interactions including the background indicator variable, the treatment indicator variable, and the country indicator variable, $M_{i} B_{i} N_{i}$ and $C_{i} B_{i} N_{i}$.

On the basis of these regressions, we can study, for each background variable, whether there are significant differences between the subgroups in terms of treatment effects:

- The estimated subgroup difference in the causal effect of introducing a difference in productivity is given by $\alpha_{M}^{B}$ (United States) and $\alpha_{M}^{B}+\delta_{M}^{B}$ (Norway).

- The estimated subgroup difference in the causal effect of introducing a cost of redistribution is given by $\alpha_{C}^{B}$ (United States) and $\alpha_{C}^{B}+\delta_{C}^{B}$ (Norway).

To illustrate, if $B_{i}$ represents political orientation, then these estimates provide us with tests of whether the causal effects of introducing a difference in productivity and a cost of redistribution are stronger for conservatives than for non-conservatives in the United States and in Norway. The regressions also provide us with estimates of whether there are statistically significant differences between the United States and Norway in how the background variables interact with introducing a difference in productivity $\left(\delta_{M}^{B}\right)$ and a cost of redistribution $\left(\delta_{C}^{B}\right)$.

\footnotetext{
${ }^{16}$ We pre-specified the following categories for the self-reported political orientation: A person in the United States is classified as conservative if he or she would have voted for the Republicans; a person in Norway is classified as conservative if he or she would have voted for Høyre or Fremskrittspartiet (the two right-wing parties presently in government in Norway). The other spectators are classified as non-conservative. We deviate slightly from the pre-analysis plan in our heterogeneity analysis for education, since we pre-specified three educational categories (not completed high school, completed high school, and higher education), but only use two in the main analysis by collapsing not completed high school and completed high school into one category (since there are very few participants who had not completed high school). In the pre-analysis plan, we also specified that we would conduct a heterogeneity analysis on income, but almost 20 percent of the participants did not self-report income. We have therefore relegated the heterogeneity analysis of income to Appendix A (Table A1), where we show that the findings are very much in line with the heterogeneity results we report for education.

${ }^{17}$ In this regression, $\mathbf{X}_{i}$ includes all background variables except the variable captured by $B_{i}$.
} 
We can further use (7) to study, for each of the background variables, whether one subgroup is systematically more inequality accepting than the other. To illustrate, we consider subgroup $B_{i}=1$ to be systematically more accepting of inequality than the other subgroup $B_{i}=0$ if the former subgroup implements more inequality in all three treatments: $\alpha^{B}>0, \alpha^{B}+\alpha_{M}^{B}>0$, and $\alpha^{B}+\alpha_{C}^{B}>0$ (United States); $\alpha^{B}+\delta^{B}>0, \alpha^{B}$ $+\alpha_{M}^{B}+\delta^{B}+\delta_{M}^{B}>0$, and $\alpha^{B}+\alpha_{C}^{B}+\delta^{B}+\delta_{C}^{B}>0$ (Norway).

Finally, (7) also serves as a robustness check of our main analysis, by showing whether a result applies to all of the pre-specified subgroups. To illustrate, we consider the introduction of a difference in productivity to increase inequality acceptance robustly across subgroups if, for each of the background variables, we find a positive treatment effect of introducing a difference in productivity as the source of inequality for both subgroups in both countries: $\alpha_{M}>0$ (subgroup $B_{i}=0$, United States), $\alpha_{M}+\alpha_{M}^{B}$ (subgroup $B_{i}=1$, United States), $\alpha_{M}+\delta_{M}>0$ (subgroup $B_{i}=0$, Norway), and $\alpha_{M}+\alpha_{M}^{B}+\delta_{M}^{B}>0$ (subgroup $B_{i}=1$, Norway).

\section{Results}

We first provide an overview of the spectator choices in the experiment, and then turn to the main analysis of the treatment effects, the prevalence of the different fairness views, and the heterogeneity and robustness analysis.

\subsection{Descriptive statistics}

Figure 2 reports histograms of the spectator behavior, for each treatment and each country. We observe that there is significant heterogeneity in the choices. In the pooled data, 52.8 percent of the spectators equalize completely between the two workers, while 23.6 percent do not redistribute at all. The worker with no initial earnings receives on average 34 percent of the total income, but less than 1 percent of the spectators assign a higher income to this worker.

There are significant differences between the Americans and the Norwegians in the pooled data. Americans are much less likely to divide equally than Norwegians (42.3 percent versus 63.3 percent), much more likely not to redistribute (32.4 percent versus 14.8 percent), and on average give significantly less to the worker with no initial earnings (29.2 percent versus 38.9 percent).

\section{[ Figure 2 about here]}

Turning to a comparison of spectator behavior across treatments, we observe from Figure 2 that there are striking differences between the luck treatment and the merit treatment. In both countries, complete equalization is the mode when luck is the source of inequality, while only a minority equalizes when a difference in productivity is the source of inequality (United States: 53.5 percent versus 15.3 percent; Norway: 
78.4 percent versus 35.6 percent). In contrast, comparing the luck treatment and the efficiency treatment, we observe that the introduction of a cost of redistribution only marginally changes the share of spectators equalizing completely (United States: 53.5 percent versus 58.1 percent; Norway: 78.4 percent versus 76.0 percent).

In Figure 3, we report the average level of inequality implemented in each of the three treatments by country. Overall, we observe that there is significantly more inequality acceptance when a difference in productivity rather than luck is the source of inequality, while the introduction of efficiency considerations does not make the spectators more willing to accept inequalities. These patterns emerge in both countries, but we observe that Norwegians implement significantly less inequality than Americans in all three treatments.

[ Figure 3 about here]

\subsection{Main analysis}

We now turn to a regression analysis of how implemented inequality depends on the treatment, the nationality of the spectator, and the interaction between treatment and nationality.

Table 3 reports regressions of implemented inequality on our main explanatory variables, separately for each of the two countries (columns 1-4) and for the pooled data with interaction effects for Norway (columns 5-6). The luck treatment with no cost of redistribution is the reference treatment in the regressions, which means that the estimated treatment effects show how much the inequality measure (equivalent to the Gini coefficient) increases when we introduce a difference in productivity as the source of inequality or introduce a cost of redistribution.

In columns 1 and 3, we observe strikingly similar patterns for the Americans and the Norwegians. In both countries, the estimated causal effect of introducing a difference in productivity as the source of inequality is large and highly significant: it increases implemented inequality by 0.195 (the United States) and 0.155 (Norway). In contrast, the estimated causal effect of introducing a cost of redistribution is small and only statistically significant for Norwegians: it increases implemented inequality by 0.011 (the United States) and 0.049 (Norway). The estimated treatment effects are almost unchanged when we control for the background variables, as shown in columns 2 and 4. We observe that both American and Norwegian conservatives implement significantly more inequality than non-conservatives, while females in both countries implement significantly less inequality than males. Interestingly, the association between socioeconomic background and implemented inequality is less systematic. We find that Americans with high education on average implement more inequality in the experiment, but we see no effect of high income in the United States. Among the Norwegians, there is no socioeconomic gradient in how much inequality is implemented in the experiment.

[ Table 3 about here] 
In columns 5 and 6 , we observe that the indicator variable for Norway is highly significant, but the estimated interaction effects are not. Column 6 reports our main specification, using equation 6 in Section 4.1. On the basis of these estimates, we can report the first set of main results:

Result 1: A difference in productivity instead of luck as the source of inequality causes a large and statistically significant increase in inequality acceptance both in the United States $\left(\alpha_{M}=0.195, p<0.001\right)$ and in Norway $\left(\alpha_{M}+\delta_{M}=0.152, p<\right.$ 0.001). The estimated country difference in the merit treatment effect is not statistically significant $\left(\delta_{M}=-0.043, p=0.290\right)$.

Result 2: A cost of redistribution causes no statistically significant increase in inequality acceptance in the United States $\left(\alpha_{C}=0.010, p=0.772\right)$, but a small and statistically significant increase in inequality acceptance in Norway $\left(\alpha_{C}+\delta_{C}=0.051\right.$, $p=0.075)$. The estimated country difference in the efficiency treatment effect is not statistically significant $\left(\delta_{C}=0.041, p=0.360\right)$.

Result 3: There is systematically more inequality acceptance in the United States than in Norway; the Americans implement more inequality than the Norwegians in all three treatments: $(\delta=-0.202, p<0.001),\left(\delta+\delta_{M}=-0.245, p<0.001\right)$, and $\left(\delta+\delta_{C}=-0.161, p<0.001\right)$.

Result 1 clearly demonstrates that the source of inequality matters for inequality acceptance in both the United States and Norway; spectators in both countries are more willing to accept an inequality between two workers if it reflects a difference in productivity rather than luck. Interestingly, however, we do not find any evidence of a difference in productivity being more important in the United States than in Norway. The introduction of a difference in productivity as the source of inequality causes a slightly larger increase in implemented inequality among the Americans than among the Norwegians, but this difference is not statistically significant.

Result 2 shows that we do not find any evidence of Americans being more efficiencyseeking than Norwegians. Overall, the spectators do not assign much importance to the cost of redistribution in their spectator choices, the treatment effect of introducing a cost of redistribution is small in both countries and only statistically significant in Norway. This finding is particularly striking in light of the fact that we introduce a significant cost of redistribution in the experiment. Taken together with Result 1, it suggests that the source of inequality is much more important than efficiency considerations for inequality acceptance; the differences in the estimated treatment effects for the introduction of a difference in productivity and the cost of redistribution are highly significant for both countries $(p<0.001)$.

Result 3 demonstrates that Americans are significantly more willing to accept inequality than Norwegians, even when they make distributive decisions in identical economic environments. In all three treatments, we observe a large difference in implemented inequality between the two countries. Thus, independent of the source of 
inequality and the cost of redistribution, the Americans are significantly more likely than Norwegians to consider inequality as fair.

In light of the theoretical model outlined in Section 3, our results show that the main difference between the American spectators and the Norwegian spectators is what they view as a fair distribution of income $(m)$, not how much weight they assign to fairness relative to efficiency $(\beta)$. To study further how Americans and Norwegians differ in their fairness considerations, we use the spectator choices in the luck and merit treatments to estimate the prevalence of the different fairness views in the populations.

[ Figure 4 about here]

As shown in Figure 4, we find large differences between the United States and Norway in the distribution of egalitarians and libertarians. The share of libertarians in the United States is more than twice the share of libertarians in Norway (29.4 percent versus 13.8 percent), while the share of egalitarians in Norway is more than twice the share of egalitarians in the United States (15.3 percent versus 35.6 percent). In both countries, we observe that meritocratism is the most prevalent fairness view (37.5 percent and 42.5 percent), while we estimate a small minority that holds other fairness views.

We can summarize these findings as follows:

Result 4: There are significant differences in fairness views between the United States and Norway, with significantly more libertarians in the United States $(p<$ $0.001)$ and significantly more egalitarians in Norway $(p<0.001)$. There is no significant difference between the two countries in the share of meritocrats $(p=0.313)$.

The fact that there is a significantly larger share of libertarians in the United States than in Norway can contribute to explain why we find that Norwegians are slightly more responsive than Americans to the introduction of a cost of redistribution (Result 2). For libertarians, the fair and the efficient distribution coincide in the efficiency treatment, and thus the introduction of a cost of redistribution has no influence on the spectator choices of the libertarians; they find it fair not to redistribute in both the luck and the efficiency treatment.

\subsection{Heterogeneity analysis}

We now turn to an analysis of the distributive behavior of different subgroups of the spectators. As specified in the pre-analysis plan, we focus on political orientation, socioeconomic background, and gender. Figure 5 reports the level of inequality acceptance by subgroup and country, while the corresponding regression analysis, using equation 7 in Section 4.1 , is reported in Table $4{ }^{18}$

\footnotetext{
${ }^{18}$ The regression analysis reported in Table 4 is the basis for all the p-values reported in this subsection. In Figure A1 in Appendix A, we report the distribution of fairness views for each of the subgroups.
} 


\section{[ Figure 5 about here]}

[ Table 4 about here]

We observe from the left panels in Figure 5 that conservatives are significantly more willing to accept inequality than non-conservatives in both countries. In the United States, the average levels of implemented inequality by conservatives and nonconservatives are 0.506 and 0.399 , respectively $(p<0.001)$ and, interestingly, we observe almost the same political difference in Norway: 0.322 versus $0.193(p<0.001)$. From column 1 in Table 4, we observe that conservatives are slightly more affected by the source of inequality than non-conservatives in both countries, but the differences are not statistically significant (United States: $p=0.583$, Norway: $p=0.513$ ). The introduction of a cost of redistribution has a large and significant effect on conservatives in Norway ( $p=0.050$ ), but only a negligible effect on non-conservatives; the estimated difference in the efficiency treatment effect is, however, not significant $(p=0.167)$. In the United States, the introduction of a cost of redistribution has no effect on either conservatives or non-conservatives.

In the middle panels in Figure 5, we compare high and low education spectators. Across all treatments, high education spectators implement more inequality than low education spectators in the United States $(0.455$ versus $0.385, p=0.017)$, while there is almost no difference between the two groups in Norway $(0.238$ versus $0.231, p=$ 0.761). The socioeconomic gradient in inequality acceptance in the United States is driven by the fact that a difference in productivity has a particularly strong effect on spectators with high education, as shown in column 2 in Table 4 . In contrast, we do not observe any difference in the merit treatment effect between the low education and high education spectators in Norway. In both countries, we observe that the high education spectators are slightly more responsive than the low education spectators to the introduction of a cost of redistribution, but these differences are not statistically significant (United States: $p=0.590$, Norway: $p=0.741$ ).

Finally, the right panels in Figure 5 provide a comparison of female and male spectators. Across all treatments, females implement less inequality than males in both countries (United States: 0.487 versus $0.380, p<0.001$; Norway: 0.264 versus 0.204 , $p=0.008$ ). In the United States, we observe that females implement less inequality than males in all treatments, while in Norway there is only a significant gender difference in the efficiency treatment. From column 3 in Table 4 , we observe that the source of inequality is more important for females than for males in both countries, but the estimated gender differences in the merit treatment effect are not statistically significant (United States: $p=0.413$, Norway: $p=0.307$ ). The introduction of a cost of redistribution has a strong effect on males in Norway $(p=0.028)$, but no effect on females $(p=0.907)$; the estimated gender difference in the efficiency treatment effect for Norway is marginally insignificant $(p=0.116)$. In the United States, the causal effect of introducing a cost of redistribution is negligible for both males and females.

The main findings of the heterogeneity analysis can be summarized as follows: 
Result 5: There are significant heterogeneities in the spectator choices:

- Political orientation: Conservative spectators are systematically more accepting of inequality than non-conservative spectators in both countries (United States: $p=0.109$ (Luck), $p=0.005$ (Merit), $p=0.135$ (Efficiency); Norway: $p=0.100$ (Luck), $p=0.003$ (Merit), $p=0.001$ (Efficiency)).

- Education: High education spectators respond more strongly than low education spectators to the introduction of a difference in productivity as the source of inequality in the United States $(p=0.064)$, while, in Norway, there is no statistically significant socioeconomic gradient in the merit treatment $(p=0.658)$. The difference between the United States and Norway in the interaction between socioeconomic background and the merit treatment is statistically significant $(p=0.087)$.

- Gender: Female spectators are systematically less accepting of inequality than male spectators in the United States ( $p=0.014$ (Luck), $p=0.100$ (Merit), $p=0.014$ (Efficiency)), while, in Norway, female spectators are only statistically significantly less inequality accepting than male spectators in the efficiency treatment ( $p=0.339$ (Luck), $p=0.639$ (Merit), $p=0.003$ (Efficiency)).

The heterogeneity analysis also serves as a robustness check of Results $1-3$, by demonstrating the extent to which the main findings apply to the different pre-specified subgroups. As summarized in the following result, these findings are remarkably consistent across subgroups.

Result 6: The causal effects of introducing a difference in productivity and a cost of redistribution on inequality acceptance and the comparison of the United States and Norway in terms of inequality acceptance are robust across subgroups in our experiment. 19

- A difference in productivity instead of luck as the source of inequality causes a large and statistically significant increase in inequality acceptance in all subgroups.

- A cost of redistribution causes no statistically significant increase in inequality acceptance in any of the subgroups, except for conservative and male spectators in Norway.

- There is systematically more inequality acceptance in the United States than in Norway in all subgroups.

\footnotetext{
${ }^{19}$ All the corresponding p-values for Result 6 are provided in Appendix A.
} 
To summarize, the experimental data robustly show that the source of inequality is significantly more important than a cost of redistribution for inequality acceptance and that Americans accept more inequality than Norwegians, even when they make distributive decisions in identical situations.

\section{Concluding remarks}

We have reported from the first large-scale comparative economic experiment on social preferences that uses nationally representative samples of participants from two countries, the United States and Norway. We introduce a novel methodological approach for collecting experimental data on nationally representative samples, by combining the infrastructure of an international online labor market platform and the infrastructure of a leading international data collection agency. The experimental design ensured that the Americans and the Norwegians made real spectator choices in identical distributive situations, where they had complete information about the source of inequality and the cost of redistribution, which allows us to identify whether the two populations differ in their social preferences. The study also provides causal evidence on how the source of inequality and a cost of redistribution shape distributive behavior, by using a between-individual design where we randomly manipulate whether luck or a difference in productivity is the source of inequality and whether there is a cost of redistribution.

We find that Americans and Norwegians differ significantly in their distributive behavior, even when they make choices in identical situations. In all treatments, the American spectators implement significantly more inequality than the Norwegian spectators. We show that this difference in inequality acceptance is largely driven by Americans and Norwegians having different fairness views; significantly more Americans endorse a libertarian fairness view, while significantly more Norwegians endorse an egalitarian fairness view. In fact, we find that the difference in inequality acceptance between the United States and Norway is significantly greater than the political difference in inequality acceptance within each of the two countries. To illustrate, the difference between Americans and Norwegians in implemented income inequality across all treatments ( 0.43 versus 0.24$)$ is substantially larger than the difference between conservatives and non-conservatives in each of the two countries (United States: 0.51 versus 0.40 ; Norway: 0.32 versus 0.19 ).

To study whether the distributive behavior in the experiment is associated with the participants' attitudes to redistributive policies, we asked them at the end of the experiment about their view on whether a society should aim to equalize incomes. As shown in the upper part of Figure 6, Americans and Norwegians respond very differently. The mode among the Americans is to completely agree with the statement that a society should not equalize incomes, while the mode among the Norwegians is to completely agree with the statement that a society should equalize incomes.

[ Figure 6]about here] 
In the bottom part of Figure 6, we show that these views are strongly associated with the distributive behavior in the experiment. ${ }^{20}$ Spectators implementing more inequality are significantly more likely to be against equalizing incomes in society. Interestingly, we also observe that the relationship between the experimental data and the survey data is equally strong for the two countries, which is indicative of fairness considerations mattering equally much for attitudes towards redistribution in the United States and in Norway.

Our findings suggest that heterogeneity in fairness preferences may be an important reason for the variation in income inequality and redistributive policies across the developed world (Alesina and Giuliano, 2011). The fact that egalitarianism is a more prominent fairness view in the Scandinavian countries and libertarianism is a more prominent fairness view in the United States may contribute to explain why the Scandinavian countries, with lower pre-tax inequality, redistribute more than the United States: Scandinavians may consider the lower level of pre-tax income inequality in their society as more unfair than Americans consider the higher level of pre-tax income inequality in their society. Consequently, if political support for redistribution is partly determined by fairness considerations, as suggested by the strong association between the spectators' willingness to redistribute in the present experiment and their attitudes to whether a society should aim to equalize incomes, then it is not surprising to see more political support for redistribution in Scandinavia than in the United States. An interesting topic for future research would be to study whether the variation in redistributive policies across societies is more strongly associated with how unfair the pre-tax income inequality is perceived to be in different societies than with the actual levels of pre-tax income inequality (Almås, Cappelen, Lind, Sørensen, and Tungodden, 2011).

The present study complements the previous important work that has focused on the role of individual beliefs in explaining differences in redistributive institutions across societies (Alesina and Angeletos, 2005; Bénabou and Tirole, 2006; Piketty, 1995). We find that meritocratism is the most prevalent fairness view both in the United States and in Norway, and beliefs about the source of inequality are essential for whether an individual with a meritocratic fairness view would consider pre-tax inequality as fair or unfair. Hence, our study suggests that both the prevalence of different fairness preferences and the beliefs people have about the source of income inequality are important in shaping the political support for redistribution in society. An interesting step for future research would be to develop models that can shed light on how fairness preferences, beliefs, and redistributive institutions jointly evolve and interact (Persson, 2002; Besley and Persson, 2011; Doepke and Zilibotti, 2014).

We find that efficiency considerations play a minor role in explaining inequality acceptance in the experiment, which suggests that efficiency considerations are less important than fairness considerations in shaping political attitudes to redistribution. Hence, there seems to be an intriguing discrepancy between the great focus on the

\footnotetext{
${ }^{20}$ In Tables A3 and A4 in Appendix A, we provide the corresponding regressions.
} 
equality-efficiency tradeoff in economics and what motivates the distributive behavior of people in general. In the experimental literature there is mixed evidence of the importance of efficiency considerations in explaining distributive behavior (Andreoni and Miller, 2002; Charness and Rabin, 2002; Engelmann and Strobel, 2004; Fehr and Schmidt, 2004). For example, a recent interesting paper (Fisman, Jakiela, and Kariv, 2015), reporting from an experiment on a large and diverse sample of Americans, finds that the way people make the equality-efficiency tradeoff predicts their political decisions: equality-focused individuals are more likely to be non-conservative. However, these different findings may reflect differences in the experimental designs. While the present study uses a between-individual spectator design, most of the other studies in the literature use a within-individual stakeholder design. We believe that both designs may capture important features of real life decision making. It would therefore be interesting in future research to study systematically how the importance of efficiency considerations vary with the role of the decision maker and the context of the distributive decision.

The present study robustly demonstrates that most people do not consider all inequalities as unfair. In particular, introducing a difference in productivity instead of luck as the source of inequality causes a large and statistically significant increase in inequality acceptance in all subgroups ${ }^{21}$ Hence, it is important to accommodate the distinction between fairness and equality in our social preference models. More research, however, is needed on how people make the distinction between fair and unfair inequalities. In the merit treatment, we focus on a distributive situation where the spectators only had information about who was more productive, not about the difference in productivity and not about their abilities and the effort they exercised. Clearly, all these other dimensions may matter when someone considers whether an inequality is fair or unfair, and it is of great importance to understand how people handle these different dimensions in their moral considerations.

We believe that the new experimental approach introduced in the present paper, combining the infrastructure of an international online market place and the infrastructure of a leading international data collection agency, opens up many avenues for future research. It can certainly facilitate studies that can extend and shed light on the robustness of our results, by varying the information offered to the spectators, the nature of the distributive situations, and the role of the decision-maker. But this approach can also be used to study a wide range of other important topics, and we thus hope that it will become an important part of the experimental toolbox in economics.

We have shown that Americans accept significantly more inequality than Scandinavians, but our findings also challenge common perceptions of these societies in the public debate. The United States is sometimes portrayed as representing cutthroat capitalism, but the present study clearly demonstrates that many Americans are con-

\footnotetext{
${ }^{21}$ This finding may also have important implications for how we think about global inequality. As shown by Milanovic (2015), global inequalities may largely be seen as reflecting differences in luck. See also Fleurbaey (2008) for an overview of the normative literature on fairness and the source of inequality.
} 
cerned with unfair inequalities. In our experiment, the majority of Americans equalize completely when the inequality is due to luck, even when there is a significant cost of redistribution. These findings are in line with recent survey evidence showing that the majority of Americans are indeed worried about unfair inequalities and demand policies that address them (Norton and Ariely, 2011; McCall, 2013). Our findings should also nuance the perception of the Scandinavian countries as representing cuddly socialism. We find that a large majority of Scandinavians accept inequalities due to a difference in productivity, what they object to are inequalities due to luck. Hence, the political support for an extensive welfare state in the Scandinavian countries may partly reflect that these policies are viewed as contributing to eliminate inequalities due to luck, without undermining inequalities due to productivity differences.

\section{References}

Aaberge, Rolf, Anders Björklund, Markus Jäntti, Mårten Palme, Peder J Pedersen, Nina Smith, and Tom Wennemo (2002). "Income inequality and income mobility in the Scandinavian countries compared to the United States," Review of Income and Wealth, 48(4): 443-469.

Aarøe, Lene and Michael Bang Petersen (2014). "Crowding out culture: Scandinavians and Americans agree on social welfare in the face of deservingness cues," The Journal of Politics, 76(03): 684-697.

Acemoglu, Daron, James A. Robinson, and Thierry Verdier (2012). "Can't we all be more like the Scandinavians? Asymmetric growth and institutions in an interdependent world," NBER Working Paper No. 18441.

Alesina, Alberto and George-Marios Angeletos (2005). "Fairness and redistribution," American Economic Review, 95(4): 960-980.

Alesina, Alberto and Paola Giuliano (2011). "Preferences for redistribution," in Jess Benhabib, Alberto Bisin, and Matthew O Jackson (eds.), "Handbook of Social Economics," volume 1, chapter 4, Amsterdam, NL: Elsevier, pp. 99-131.

Alesina, Alberto, Edward L. Glaeser, and Bruce Sacerdote (2001). "Why doesn't the United States have a European-style welfare state?" Brookings Papers on Economic Activity, 2001(1): 187-254.

Alesina, Alberto and Edward Ludwig Glaeser (2004). Fighting poverty in the US and Europe: A world of difference, Oxford, UK: Oxford University Press.

Almås, Ingvild, Alexander W. Cappelen, Jo Thori Lind, Erik Ø. Sørensen, and Bertil Tungodden (2011). "Measuring unfair (in)equality," Journal of Public Economics, 95(7-8): 488-499. 
Almås, Ingvild, Alexander W. Cappelen, Erik $\varnothing$. Sørensen, and Bertil Tungodden (2010). "Fairness and the development of inequality acceptance," Science, 328(5982): 1176-1178.

Andreoni, James, Deniz Aydın, Blake Barton, B Douglas Bernheim, and Jeffrey Naecker (2016). "When fair isn't fair: Sophisticated time inconsistency in social preferences," mimeo.

Andreoni, James and John Miller (2002). "Giving according to GARP: an experimental test of the consistency of preferences for altruism," Econometrica, 70(2): 737753.

Arrow, Kenneth, Samuel Bowles, and Steven Durlauf (eds.) (2000). Meritocracy and Economic Inequality, Princeton, NJ: Princeton University Press.

Ashok, Vivekinan, Ilyana Kuzimko, and Ebonya Washington (2015). "Support for redistribution in an age of rising inequality: New stylized facts and some tentative explanations," Brookings Papers on Economic Activity.

Atkinson, Anthony, Thomas Piketty, and Emanuel Saez (2011). "Top incomes in the long run of history," Journal of Economic Literature, 49(1): 3-71.

Austen-Smith, David (2000). "Redistributing income under proportional representation," Journal of Political Economy, 108(6): 1235-1269.

Barrett, H. Clark, Alex Bolyanatz, Alyssa N. Crittenden, Daniel M.T. Fessler, Simon Fitzpatrick, Michael Gurven, Joseph Henrich, Martin Kanovsky, Geoff Kushnick, Anne Pisor, Brooke Scelza, Stephen Stich, Chris von Rueden, Wanying Zhaog, and Stephen Laurence (2016). "Small-scale societies exhibit fundamental variation in the role of intentions in moral judgment," Proceedings of the National Academy of Sciences, 133(17): 4688-4693.

Barth, Erling, Karl O Moene, and Fredrik Willumsen (2014). "The Scandinavian model - an interpretation," Journal of Public Economics, 117: 60-72.

Bartling, Björn, Roberto A. Weber, and Lan Yao (2015). "Do markets erode social responsibility?" Quarterly Journal of Economics, 130(1): 219-266.

Bartling, Björn, Ernst Fehr, and Klaus M. Schmidt (2012). "Screening, competition, and job design: Economic origins of good jobs," American Economic Review, 102(2): 834-864.

Bellemare, Charles, Sabine Kröger, and Arthur van Soest (2008). "Measuring inequity aversion in a heterogeneous population using experimental decisions and subjective probabilities," Econometrica, 76(4): 815-839. 
Bénabou, Roland and Jean Tirole (2006). "Belief in a just world and redistributive politics," Quarterly Journal of Economics, 12(2): 699-746.

Besley, Timothy and Torsten Persson (2011). Pillars of prosperity: The political economics of development clusters, NJ: Princeton University Press.

Bolton, Gary E. and Axel Ockenfels (2000). "ERC: A theory of equity, reciprocity, and competition," American Economic Review, 90(1): 166-193.

Booth, Michael (2016). "Stop the Scandimania: Nordic nations aren't the utopias they're made out to be," The Washington Post, http://wpo.st/T-ZY11.

Brennan, Jason, Bas van der Vossen, and David Schmidtz (eds.) (2016). The Routledge Handbook of Libertarianism, New York: Routledge.

Cappelen, Alexander W., Astri Drange Hole, Erik Ø. Sørensen, and Bertil Tungodden (2007). "The pluralism of fairness ideals: An experimental approach," American Economic Review, 97(3): 818-827.

Cappelen, Alexander W., James Konow, Erik Ø. Sørensen, and Bertil Tungodden (2013a). "Just luck: An experimental study of risk taking and fairness," American Economic Review, 103(3): 1398-1413.

Cappelen, Alexander W., Karl O. Moene, Erik Ø. Sørensen, and Bertil Tungodden (2013b). "Needs versus entitlements: An international fairness experiment," Journal of the European Economic Association, 11(3): 574-598.

Cappelen, Alexander W., Knut Nygaard, Erik Ø. Sørensen, and Bertil Tungodden (2015). "Social preferences in the lab: A comparison of students and a representative population," Scandinavian Journal of Economics, 117(4): 1306-1326.

Cappelen, Alexander W., Erik Ø. Sørensen, and Bertil Tungodden (2010). "Responsibility for what? Fairness and individual responsibility," European Economic Review, 54(3): 429-441.

Charness, Gary and Matthew Rabin (2002). "Understanding social preferences with simple tests," Quarterly Journal of Economics, 117(3): 817-869.

Chen, Daniel L. and Jo Thori Lind (2015). "The political economy of beliefs," Discussion Paper, University of Oslo.

Corneo, Giacomo and Hans Peter Grüner (2002). "Individual preferences for political redistribution,” Journal of Public Economics, 83(1): 83-107.

Doepke, Matthias and Fabrizio Zilibotti (2014). "Parenting with style: Altruism and paternalism in intergenerational preference transmission," NBER Working Paper 20214, National Bureau of Economic Research. 
Edlund, Jonas (1999). "Trust in government and welfare regimes: Attitudes to redistribution and financial cheating in the USA and Norway," European Journal of Political Research, 35(3): 341-370.

Engelmann, Dirk and Martin Strobel (2004). "Inequality aversion, efficiency, and maximin preferences in simple distribution experiments," American Economic Review, 94(4): 857-869.

Engelmann, Dirk and Martin Strobel (2006). "Inequality aversion, efficiency, and maximin preferences in simple distribution experiments: Reply," American Economic Review, 96(5): 1918-1923.

Falk, Armin, Anke Becker, Thomas Dohmen, Benjamin Enke, David Huffman, and Uwe Sunde (2015). "The nature and predictive power of preferences: Global evidence," IZA DP 9504, IZA.

Falk, Armin and Nora Szech (2013). "Morals and markets," Science, 340(6133): 707711.

Farina, Francesco, Gianluca Grimalda, and Ulrich Schmidt (2016). "Preferences for redistribution in the US, Italy, Norway: An experimental study," Working paper.

Fehr, Ernst, Helen Bernhard, and Bettina Rockenbach (2008). "Egalitarianism in young children," Nature, 454(7208): 1079-1083.

Fehr, Ernst, Daniela Glätzle-Rützler, and Matthias Sutter (2013). "The development of egalitarianism, altruism, spite and parochialism in childhood and adolescence," European Economic Review, 64(1): 369-383.

Fehr, Ernst, G. Kirchsteiger, and Arno Riedl (1993). "Does fairness prevent market clearing? An experimental investigation," Quarterly Journal of Economics, 108(2): 437-459.

Fehr, Ernst, Michael Naef, and Klaus M. Schmidt (2006). "Inequality aversion, efficiency, and maximin preferences in simple distribution experiments: Comment," American Economic Review, 96(5): 1912-1917.

Fehr, Ernst and Klaus M. Schmidt (1999). "A theory of fairness, competition and cooperation,” Quarterly Journal of Economics, 114(3): 817-868.

Fehr, Ernst and Klaus M. Schmidt (2004). "The role of equality, efficiency, and Rawlsian motives in social preferences: A reply to Engelmann and Strobel," mimeo.

Fisman, Raymond, Pamela Jakiela, and Shachar Kariv (2015). "Distributional preferences and political behavior," mimeo. 
Fleurbaey, Marc (2008). Fairness, Responsibility, and Welfare, Oxford, UK: Oxford University Press.

Fochesato, Mattia and Samuel Bowles (2015). "Nordic exceptionalism? Social democratic egalitarianism in world-historic perspective," Journal of Public Economics, 127: 30-44.

Fong, Christina (2001). "Social preferences, self-interest, and the demand for redistribution," Journal of Public Economics, 82(2): 225-246.

Henrich, Joseph, Robert Boyd, Samuel Bowles, Colin Camerer, Ernst Fehr, Herbert Gintis, Richard McElreath, Michael Alvard, Abigail Barr, Jean Ensminger, Natalie Smith Henrich, Kim Hill, Francisco Gil-White, Michael Gurven, Frank W. Marlowe, John Q. Patton, and David Tracer (2005). "“Economic man" in crosscultural perspective: Behavioral experiments in 15 small-scale societies," Brain and Behavioral Science, 28(6): 795-815.

Henrich, Joseph, Jean Ensminger, Richard McElreath, Abigail Barr, Clark Barrett, Alexander Bolyanatz, Juan Camilo Cardenas, Michael Gurven, Edwins Gwako, Natalie Henrich, Carolyn Lesorogol, Frank Marlowe, David Tracer, and John Ziker (2010). "Markets, religion, community size, and the evolution of fairness and punishment," Science, 327(5972): 1480-1484.

Irwin, Neil (2014). "A big safety net and strong job market can coexist. Just ask Scandinavia." The New York Times, http://nyti.ms/1GsVvSY.

Jakiela, Pamela (2015). "How fair shares compare: Experimental evidence from two cultures," Journal of Economic Behavior \& Organization, 118: 40-54.

Jantti, Markus, Bernt Bratsberg, Knut Roed, Oddbjorn Raaum, Robin Naylor, Eva Osterbacka, Anders Bjorklund, and Tor Eriksson (2006). "American exceptionalism in a new light: A comparison of intergenerational earnings mobility in the Nordic countries, the United Kingdom and the United States," IZA Discussion Paper No. 1938.

Kiatpongsan, Sorapop and Michael I Norton (2014). "How much (more) should CEOs make? A universal desire for more equal pay," Perspectives on Psychological Science, 9(6): 587-593.

Kleven, Henrik Jacobsen (2014). "How can Scandinavians tax so much?" The Journal of Economic Perspectives, 28(4): 77-98.

Konow, James (1996). "A positive theory of economic fairness," Journal of Economic Behavior and Organization, 31(1): 13-35.

Konow, James (2000). "Fair Shares: Accountability and Cognitive Dissonance in Allocation Decisions," American Economic Review, 90(4): 1072-1091. 
Kuziemko, Ilyana, Michael I. Norton, Emmanuel Saez, and Stefanie Stantcheva (2015). "How elastic are preferences for redistribution? Evidence from randomized survey experiments," American Economic Review, 105(4): 1478-1508.

Linos, Katerina and Martin West (2003). "Self-interest, social beliefs, and attitudes to redistribution. Re-addressing the issue of cross-national variation," European Sociological Review, 19(4): 393-409.

Luttmer, Erzo FP and Monica Singhal (2011). "Culture, context, and the taste for redistribution," American Economic Journal: Economic Policy, 3(1): 157-179.

McCall, Leslie (2013). The undeserving rich: American beliefs about inequality, opportunity, and redistribution, Cambridge University Press.

Milanovic, Branko (2015). "Global inequality of opportunity: How much of our income is determined by where we live?" Review of Economics and Statistics, 97(2): 452-460.

Moene, Karl Ove and Michael Wallerstein (1997). "Pay inequality," Journal of Labor Economics, 15(3): 403-430.

Norton, Michael I. and Dan Ariely (2011). "Building a better America—one wealth quintile at a time," Perspectives on Psychological Science, 6(1): 9-12.

Nozick, Robert (1974). Anarchy, State, and Utopia, New York: Basic Books.

OECD (2015). "OECD stat export, http : //stats.oecd.org/index.aspx?datasetcode $=$ idd," downloaded February 23, 2015.

Osberg, Lars and Timothy Smeeding (2006). “"Fair” inequality? Attitudes toward pay differentials: the United States in comparative perspective," American sociological review, 71(3): 450-473.

Persson, Torsten (2002). "Do political institutions shape economic policy?" Econometrica, 70(3): 883-905.

Piketty, Thomas (1995). "Social mobility and redistributive politics," Quarterly Journal of Economics, 110(3): 551-584.

Piketty, Thomas, Emmanuel Saez, and Stefanie Stantcheva (2014). "Optimal taxation of top labor incomes: A tale of three elasticities," American Economic Journal: Economic Policy, 6(1): 230-271.

Rogerson, Richard (2007). "Taxation and market work: is Scandinavia an outlier?" Economic Theory, 32(1): 59-85.

Samuelson, Paul A. (1954). "The transfer problem and transport costs, ii: Analysis of effects of trade impediments," Economic Journal, 64(254): 265-289. 
Scruggs, Lyle, Detlef Jahn, and Kati Kuitto (2014). "Comparative welfare entitlements dataset 2. Version 2014-03," University of Connecticut \& University of Greifswald.

Smeets, Paul, Rob Bauer, and Uri Gneezy (2015). "Giving behavior of millionaires," Proceedings of the National Academy of Sciences, 112(34): 10641-10644.

Stiglitz, Joseph E (2015). "Leaders and followers: Perspectives on the Nordic model and the economics of innovation," Journal of Public Economics, 127: 3-16.

Svallfors, Stefan (1997). "Worlds of welfare and attitudes to redistribution: A comparison of eight western nations," European Sociological Review, 13(3): 283-304.

Tassinari, Fabrizio (2013). "Why Nordic nations are a role model for us all," CNN, http://globalpublicsquare.blogs.cnn.com/2013/02/11/ why-nordic-nations-are-a-role-model-for-us-all/. 
Figure 1: Income inequality in OECD countries

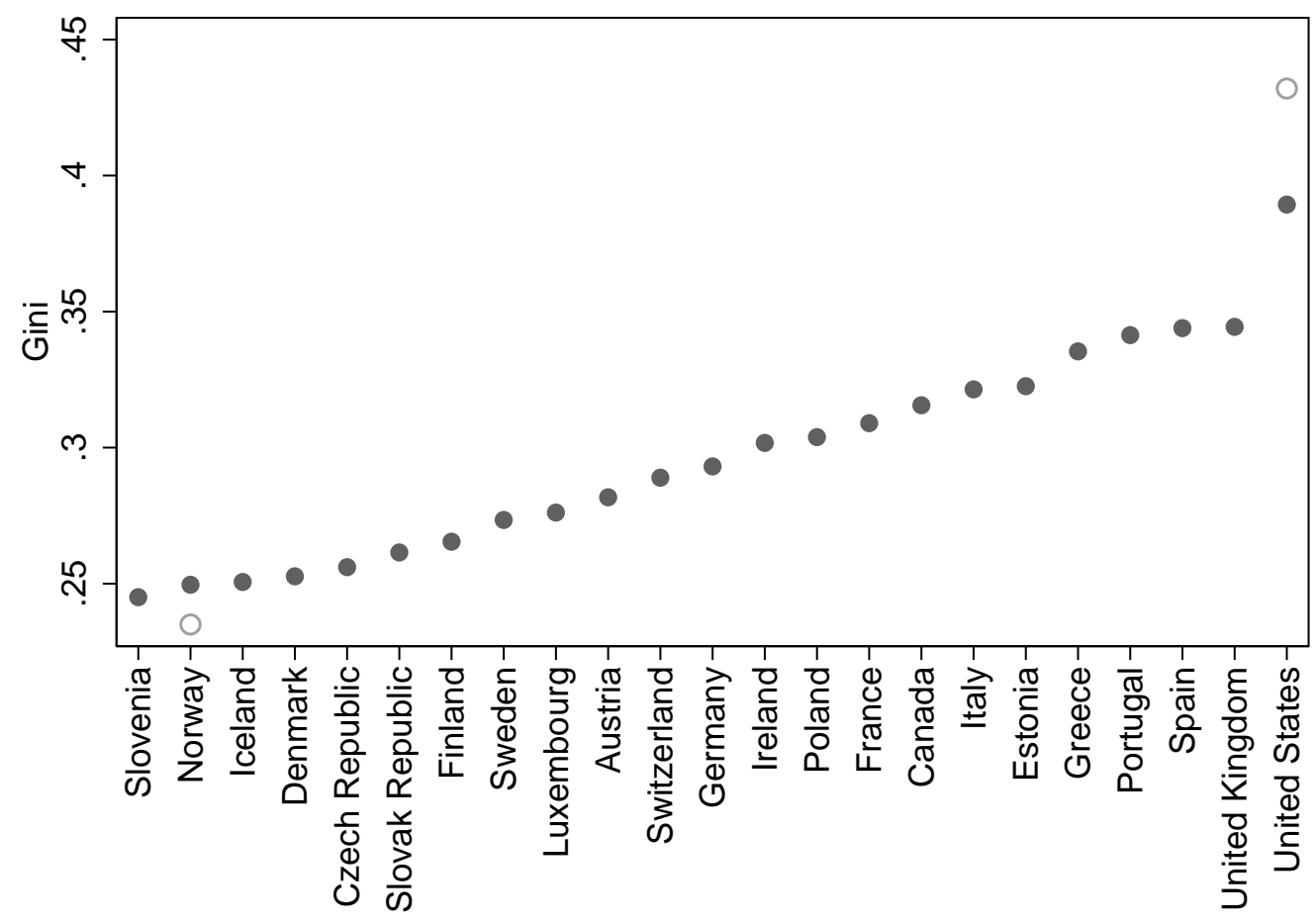

Note: The figure shows the Gini index for disposable income for the countries in Europe and North America in which this index is available for 2011 from the OECD (OECD, 2015), as well as the average Gini implemented in the experiment. The Gini from the OECD is indicated by a solid circle and the Gini from the experiment is indicated by a hollow circle. 
Figure 2: Distribution of choices

\section{United States}
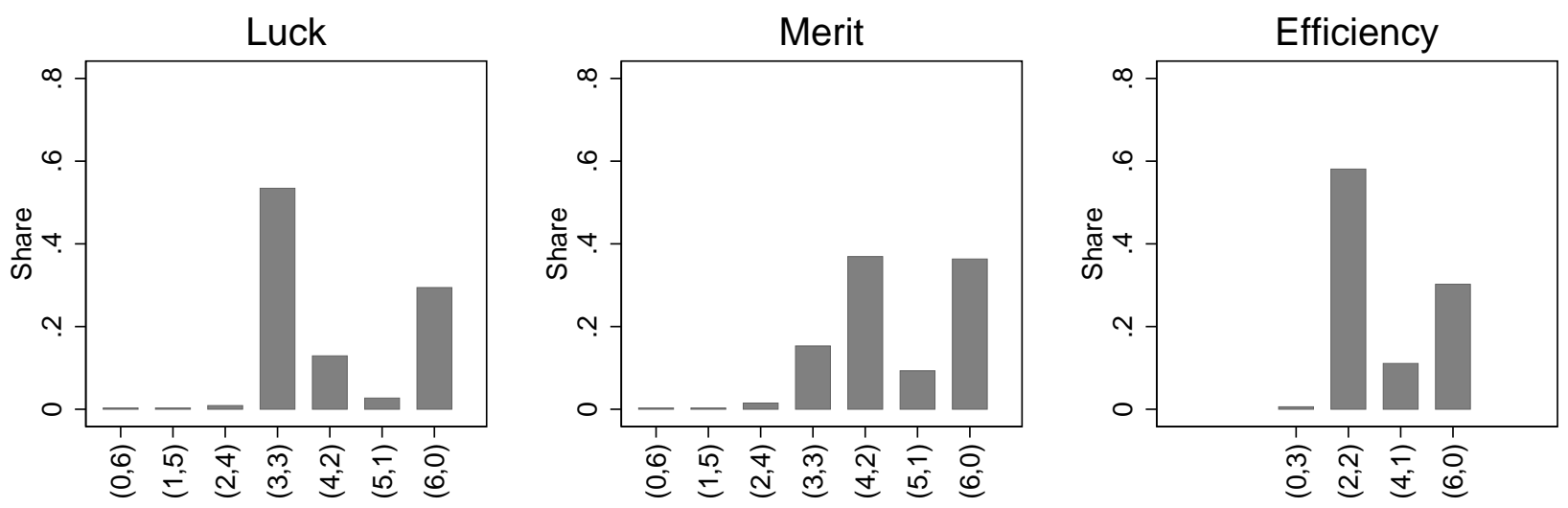

\section{Norway}
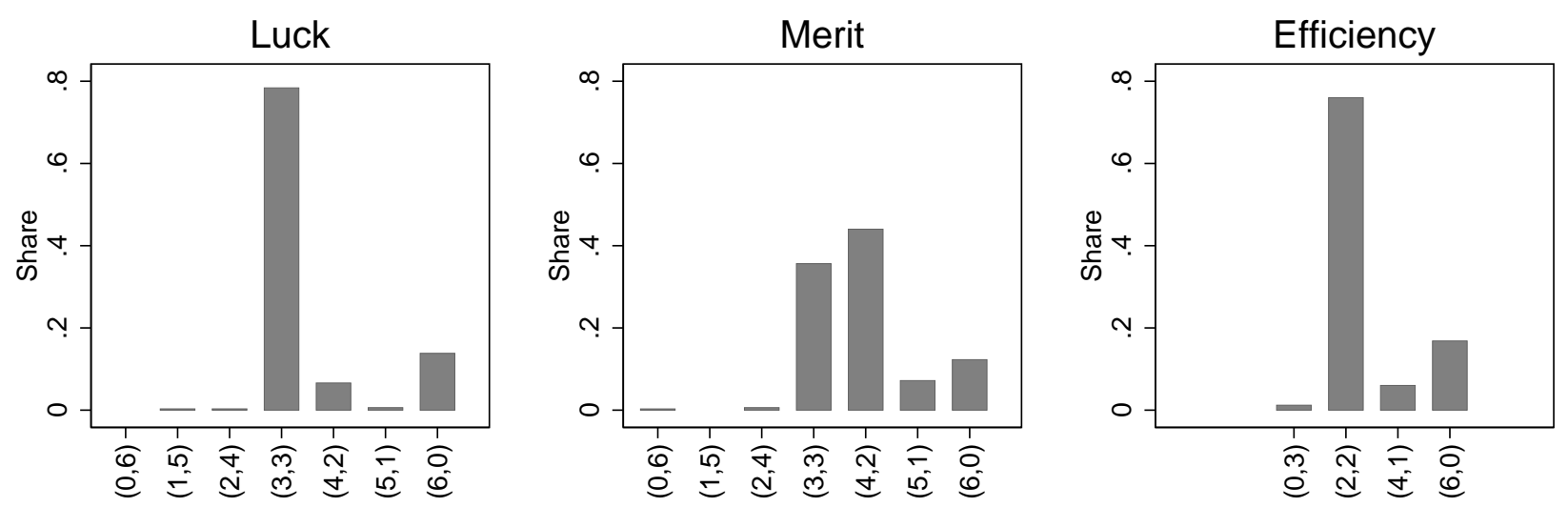

Note: The figure shows the share of spectators who choose the alternative distributions by treatment and by country. 
Figure 3: Implemented inequality in the United States and Norway
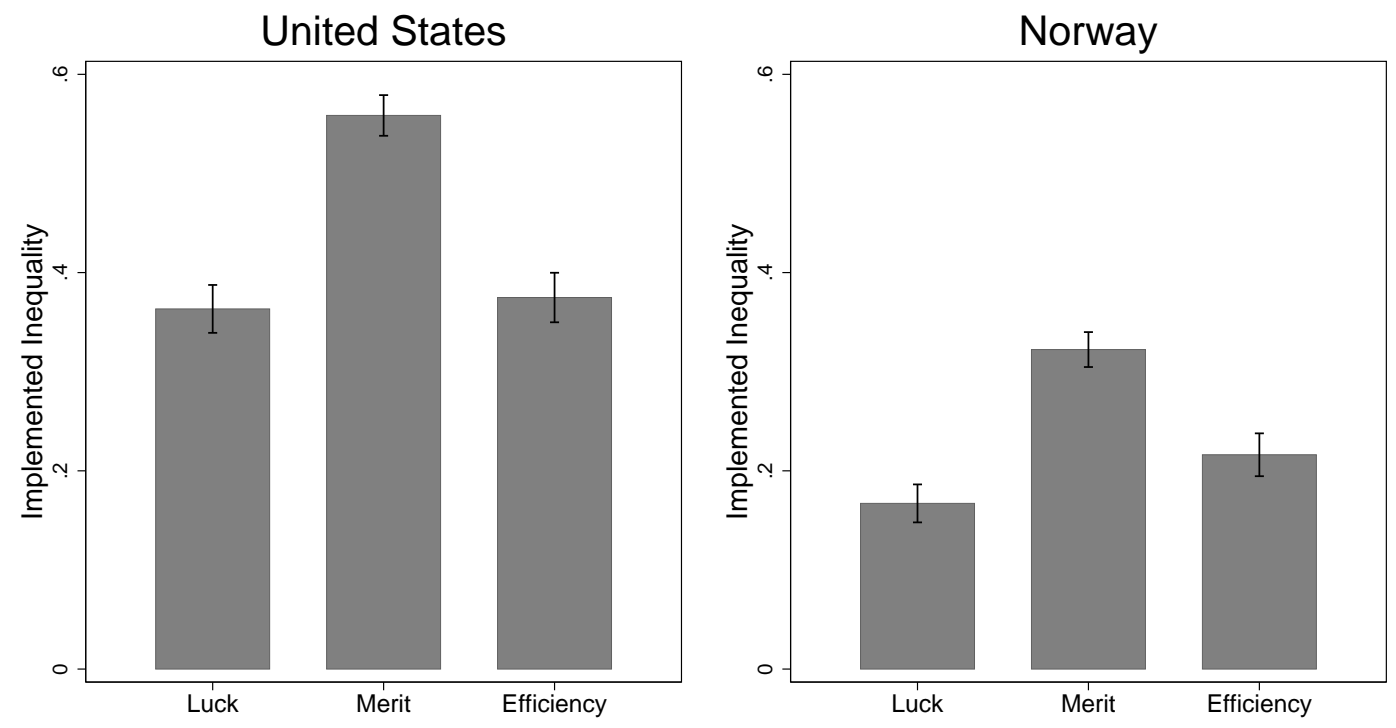

Note: The figure shows the average level of implemented inequality (as defined in Equation (5) ) by the American and the Norwegian spectators in each of the three treatments. The standard errors are indicated by the bars. 
Figure 4: Fairness types in the United States and Norway

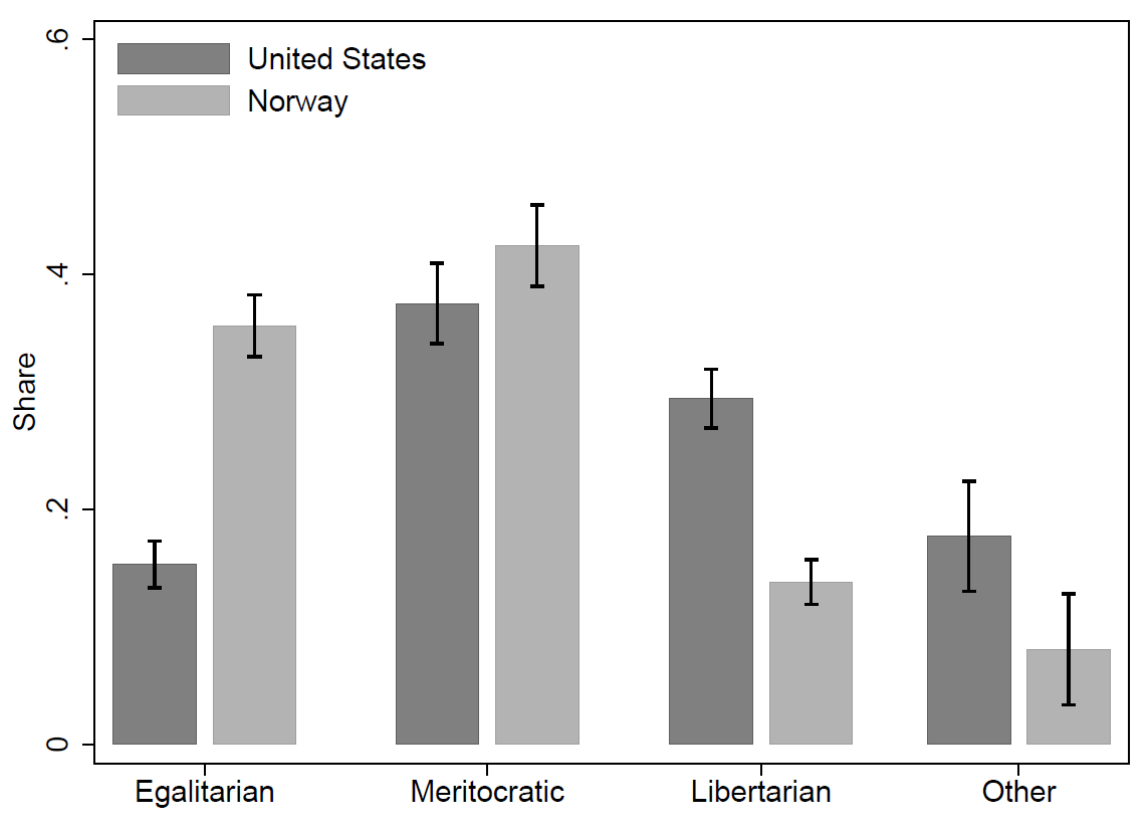

Note: The figure shows the share of the different fairness types in Norway and the United States. The fairness types are defined in Section 3. The standard errors are indicated by the bars. 
Figure 5: Implemented inequality for subgroups

\section{United States}
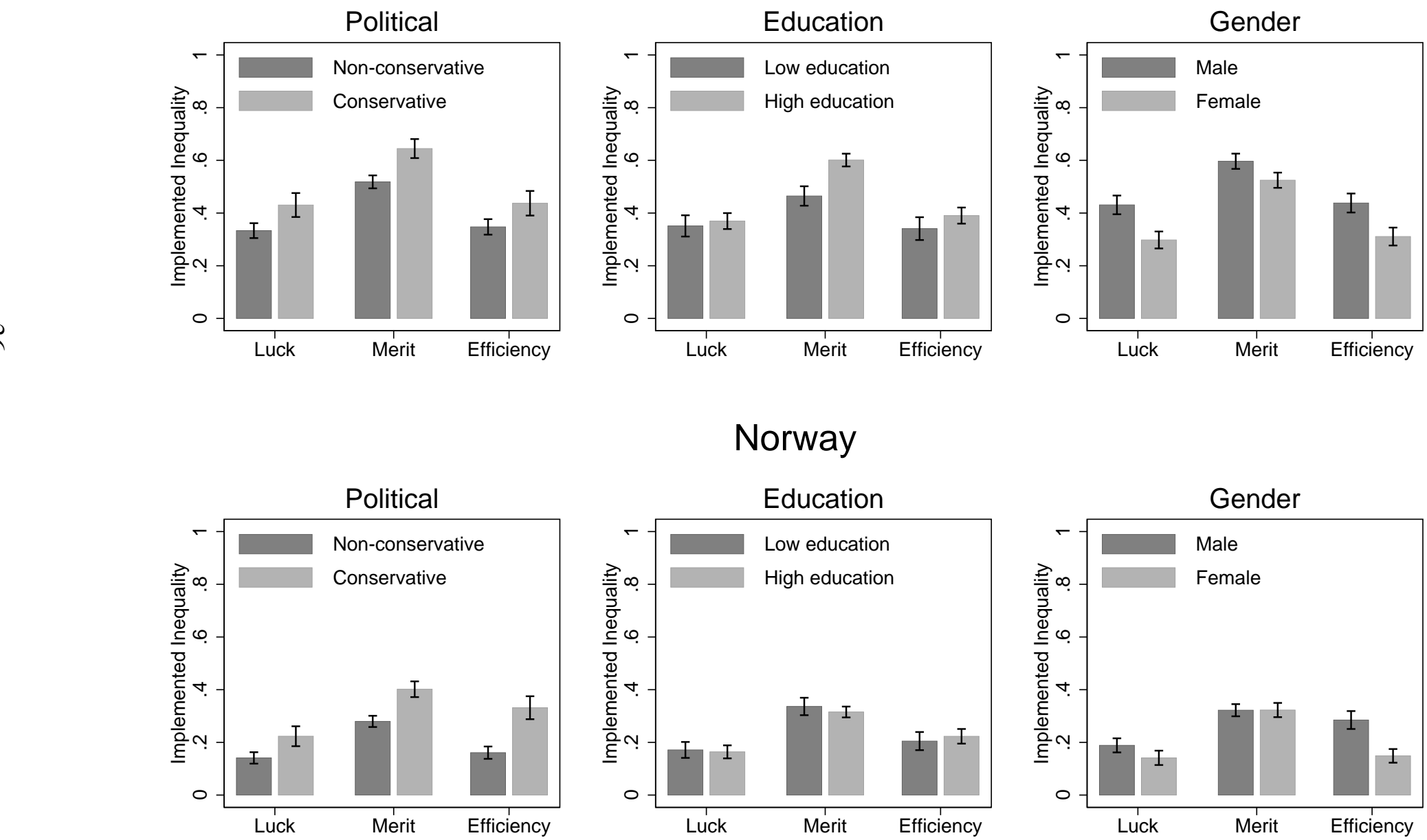

Note: The figure shows the average level of implemented inequality (as defined in Equation (5) by the American and the Norwegian spectators for each subgroup in the three treatments. The standard errors are indicated by the bars. 
Figure 6: The general support for equalizing policies and implemented inequality in experiment
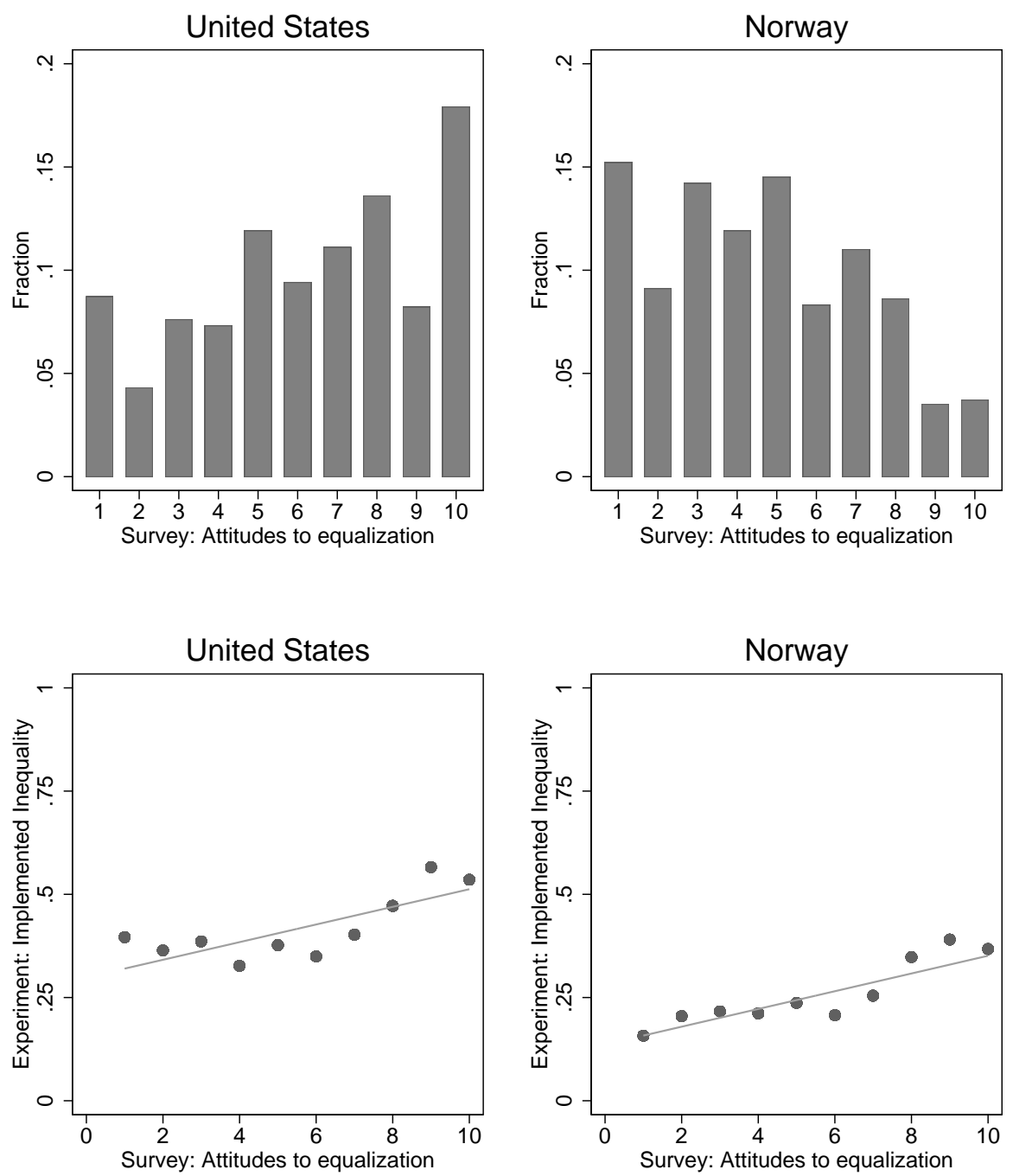

Note: The upper panel shows the distribution of general support for equalizing policies measured by the following survey question: We now want you to indicate to what extent you agree with the following statements: 1 means that you agree completely with the statement "A society should aim to equalize incomes", 10 means that you agree completely with the statement "A society should not aim to equalize incomes", and the numbers in between indicate the extent to which you agree or disagree with the statements. The lower panel shows the relation between implemented inequality in the experiment and the general support for redistribution revealed in the survey. The line represents the linear fit based on the individual observations (coefficient United States: 0.021, $p<0.001$, coefficient Norway: 0.022, $p<0.001$ ). The dots indicate the mean level of implemented inequality for each survey response on equalization on a scale from 1 to 10 . 
Table 1: Sequence of events in the experiment

Stage of experiment

1. Work stage: Workers complete an assignment.

$\underset{\infty}{\omega} \quad$ 2. Earnings stage: Workers matched in pairs. Assigned initial earnings according to treatment.

3. Redistribution stage: Each spectator decides for one pair of workers whether and how much to redistribute.

4. Payment stage: Workers in the pair paid according to the decision of the spectator.

Note: The table provides an overview of the main stages in the experiment. 
Table 2: Descriptive statistics - background variables for the spectator sample

\section{United States Norway}

Female (share)

$0.51 \quad 0.48$

Age (year)

Median

p10

$44 \quad 53$

p90

$23 \quad 27$

$67 \quad 72$

Eduction (share)

High school or less $\quad 0.32 \quad 0.38$

$\begin{array}{lll}\text { College } & 0.38 & 0.29\end{array}$

High education $\quad 0.30 \quad 0.33$

Income (USD)

Median $\quad 5500 \quad 5385$

p10 $1500 \quad 2071$

p90 $16250 \quad 8700$

Conservative (share) $\quad 0.31 \quad 0.33$

Number of participants $\quad 1000 \quad 1000$

Note: The table displays the descriptive statistics for the background variables of the spectator sample. The income variable is monthly post-tax income in USD (PPP adjusted using price of consumption for year 2011, Penn World Table 8.0) and given in standard categories where we use the mid-point in the category (see Table A2 in Appendix A for a listing of income categories). A participant is classified as conservative if he or she would have voted for the Republican party in the United States or one of two right-wing parties in Norway (Høyre or Fremskrittspartiet). 
Table 3: Regression results on implemented inequality

\begin{tabular}{|c|c|c|c|c|c|c|}
\hline & United States & United States & Norway & Norway & Pooled & Pooled \\
\hline Merit & $\begin{array}{l}0.195 * * * \\
(0.032)\end{array}$ & $\begin{array}{l}0.193 * * * \\
(0.031)\end{array}$ & $\begin{array}{l}0.155^{* * *} \\
(0.026)\end{array}$ & $\begin{array}{l}0.156^{* * * *} \\
(0.026)\end{array}$ & $\begin{array}{l}0.195 * * * \\
(0.032)\end{array}$ & $\begin{array}{l}0.195 * * * \\
(0.031)\end{array}$ \\
\hline Cost & $\begin{array}{l}0.011 \\
(0.035)\end{array}$ & $\begin{array}{l}0.006 \\
(0.034)\end{array}$ & $\begin{array}{l}0.049 * \\
(0.029)\end{array}$ & $\begin{array}{l}0.053 * \\
(0.029)\end{array}$ & $\begin{array}{l}0.011 \\
(0.035)\end{array}$ & $\begin{array}{l}0.010 \\
(0.034)\end{array}$ \\
\hline Merit x Norway & & & & & $\begin{array}{l}-0.040 \\
(0.041)\end{array}$ & $\begin{array}{l}-0.043 \\
(0.041)\end{array}$ \\
\hline Cost x Norway & & & & & $\begin{array}{l}0.038 \\
(0.045)\end{array}$ & $\begin{array}{l}0.041 \\
(0.045)\end{array}$ \\
\hline Norway & & & & & $\begin{array}{l}-0.196 * * * \\
(0.031)\end{array}$ & $\begin{array}{l}-0.202 * * * \\
(0.031)\end{array}$ \\
\hline High income & & $\begin{array}{l}-0.020 \\
(0.030)\end{array}$ & & $\begin{array}{l}-0.027 \\
(0.025)\end{array}$ & & $\begin{array}{l}-0.016 \\
(0.019)\end{array}$ \\
\hline High education & & $\begin{array}{l}0.058 * * \\
(0.029)\end{array}$ & & $\begin{array}{l}0.004 \\
(0.023)\end{array}$ & & $\begin{array}{l}0.030 \\
(0.018)\end{array}$ \\
\hline Female & & $\begin{array}{l}-0.101 * * * \\
(0.027)\end{array}$ & & $\begin{array}{l}-0.054 * * \\
(0.022)\end{array}$ & & $\begin{array}{l}-0.076^{* * * *} \\
(0.018)\end{array}$ \\
\hline Conservative & & $\begin{array}{l}0.085^{* * *} \\
(0.029)\end{array}$ & & $\begin{array}{l}0.122 * * * \\
(0.025)\end{array}$ & & $\begin{array}{l}0.106^{* * * *} \\
(0.019)\end{array}$ \\
\hline Age & & $\begin{array}{l}0.002 * * \\
(0.001)\end{array}$ & & $\begin{array}{l}-0.001 * * \\
(0.001)\end{array}$ & & $\begin{array}{l}0.000 \\
(0.001)\end{array}$ \\
\hline Constant & $\begin{array}{l}0.363^{* * *} \\
(0.024)\end{array}$ & $\begin{array}{l}0.271 * * * \\
(0.047)\end{array}$ & $\begin{array}{l}0.167 * * * \\
(0.019)\end{array}$ & $\begin{array}{l}0.230 * * * \\
(0.046)\end{array}$ & $\begin{array}{l}0.363 * * * \\
(0.024)\end{array}$ & $\begin{array}{l}0.343 * * * \\
(0.037)\end{array}$ \\
\hline $\begin{array}{l}\text { Observations } \\
R^{2}\end{array}$ & $\begin{array}{l}1000 \\
0.042\end{array}$ & $\begin{array}{l}1000 \\
0.079\end{array}$ & $\begin{array}{l}1000 \\
0.032\end{array}$ & $\begin{array}{l}1000 \\
0.069\end{array}$ & $\begin{array}{l}2000 \\
0.093\end{array}$ & $\begin{array}{l}2000 \\
0.120\end{array}$ \\
\hline \multicolumn{7}{|l|}{ lincom: } \\
\hline Merit (Norway) & & & & & $\begin{array}{l}0.155^{* * *} \\
(0.026)\end{array}$ & $\begin{array}{l}0.152 * * * \\
(0.026)\end{array}$ \\
\hline Efficiency (Norway) & & & & & $\begin{array}{l}0.049 * \\
(0.029)\end{array}$ & $\begin{array}{l}0.051^{*} \\
(0.028)\end{array}$ \\
\hline
\end{tabular}

Note: The table reports results from robust OLS regressions of implemented inequality on a set of explanatory variables. "Merit" is an indicator variable taking the value one if the spectator is in the merit treatment. "Cost" is an indicator variable taking the value one if the spectator is in the luck treatment. "Norway" is an indicator variable taking the value one if a spectator is from Norway. "Merit x Norway" and "Cost x Norway" are interactions between the respective treatments and Norway. "Conservative" is an indicator variable for being conservative, "High income" is an indicator variable for having income higher than the median in the country, and "High education" is an indicator variable for having more than high school education. "Female" is an indicator variable for being female and "Age" is given in years. We also include an indicator variable for missing income (which takes the value one for 132 individuals in the United States and 200 individuals in Norway). Standard errors in parentheses, $* p<0.1$, ** $p<0.05$, *** $p<0.01$. 
Table 4: Heterogeneity analysis on implemented inequality

\begin{tabular}{|c|c|c|c|}
\hline & $\begin{array}{c}\text { Political } \\
(\mathrm{B}=1 \text { if Conservative })\end{array}$ & $\begin{array}{c}\text { Education } \\
(\mathrm{B}=1 \text { if } \text { High })\end{array}$ & $\begin{array}{c}\text { Gender } \\
(\mathrm{B}=1 \text { if Female })\end{array}$ \\
\hline Merit & $\begin{array}{l}0.183 * * * \\
(0.037)\end{array}$ & $\begin{array}{l}0.111 * * \\
(0.054)\end{array}$ & $\begin{array}{l}0.168 * * * \\
(0.045)\end{array}$ \\
\hline Cost & $\begin{array}{l}0.011 \\
(0.041)\end{array}$ & $\begin{array}{l}-0.017 \\
(0.060)\end{array}$ & $\begin{array}{l}0.012 \\
(0.050)\end{array}$ \\
\hline Merit x Norway & $\begin{array}{l}-0.043 \\
(0.049)\end{array}$ & $\begin{array}{l}0.060 \\
(0.071)\end{array}$ & $\begin{array}{l}-0.042 \\
(0.057)\end{array}$ \\
\hline Cost x Norway & $\begin{array}{l}0.011 \\
(0.052)\end{array}$ & $\begin{array}{l}0.057 \\
(0.075)\end{array}$ & $\begin{array}{l}0.082 \\
(0.066)\end{array}$ \\
\hline Merit x B & $\begin{array}{l}0.037 \\
(0.068)\end{array}$ & $\begin{array}{l}0.123^{*} \\
(0.066)\end{array}$ & $\begin{array}{l}0.051 \\
(0.063)\end{array}$ \\
\hline Cost $\mathrm{x} B$ & $\begin{array}{l}-0.003 \\
(0.076)\end{array}$ & $\begin{array}{l}0.039 \\
(0.073)\end{array}$ & $\begin{array}{l}-0.004 \\
(0.069)\end{array}$ \\
\hline Merit x B x Norway & $\begin{array}{l}0.000 \\
(0.089)\end{array}$ & $\begin{array}{l}-0.147 * \\
(0.086)\end{array}$ & $\begin{array}{l}0.002 \\
(0.081)\end{array}$ \\
\hline Cost x B x Norway & $\begin{array}{l}0.093 \\
(0.101)\end{array}$ & $\begin{array}{l}-0.020 \\
(0.093)\end{array}$ & $\begin{array}{l}-0.085 \\
(0.089)\end{array}$ \\
\hline B x Norway & $\begin{array}{l}-0.013 \\
(0.068)\end{array}$ & $\begin{array}{l}-0.010 \\
(0.064)\end{array}$ & $\begin{array}{l}0.081 \\
(0.061)\end{array}$ \\
\hline Norway & $\begin{array}{l}-0.198 * * * \\
(0.036)\end{array}$ & $\begin{array}{l}-0.198 * * * \\
(0.051)\end{array}$ & $\begin{array}{l}-0.241 * * * \\
(0.044)\end{array}$ \\
\hline $\mathrm{B}$ & $\begin{array}{l}0.085 \\
(0.053)\end{array}$ & $\begin{array}{l}0.010 \\
(0.051)\end{array}$ & $\begin{array}{l}-0.118 * * \\
(0.048)\end{array}$ \\
\hline Constant & $\begin{array}{l}0.349 * * * \\
(0.039)\end{array}$ & $\begin{array}{l}0.355^{* * *} \\
(0.049)\end{array}$ & $\begin{array}{l}0.363 * * * \\
(0.044)\end{array}$ \\
\hline With controls & $X$ & $X$ & $\mathrm{X}$ \\
\hline $\begin{array}{l}\text { Observations } \\
R^{2}\end{array}$ & $\begin{array}{l}2000 \\
0.121\end{array}$ & $\begin{array}{l}2000 \\
0.123\end{array}$ & $\begin{array}{l}2000 \\
0.124\end{array}$ \\
\hline \multicolumn{4}{|l|}{ lincom: } \\
\hline Merit (US, B) & $\begin{array}{l}0.220 * * * \\
(0.057)\end{array}$ & $\begin{array}{l}0.233 * * * \\
(0.038)\end{array}$ & $\begin{array}{l}0.220 * * * \\
(0.043)\end{array}$ \\
\hline Cost (US, B) & $\begin{array}{l}0.008 \\
(0.064)\end{array}$ & $\begin{array}{l}0.023 \\
(0.042)\end{array}$ & $\begin{array}{l}0.007 \\
(0.047)\end{array}$ \\
\hline Merit (Norway, not B) & $\begin{array}{l}0.140 * * * \\
(0.031)\end{array}$ & $\begin{array}{l}0.171 * * * \\
(0.045)\end{array}$ & $\begin{array}{l}0.126 * * * \\
(0.035)\end{array}$ \\
\hline Merit (Norway, B) & $\begin{array}{l}0.177 * * * \\
(0.048)\end{array}$ & $\begin{array}{l}0.146 * * * \\
(0.032)\end{array}$ & $\begin{array}{l}0.179 * * * \\
(0.038)\end{array}$ \\
\hline Cost (Norway, not B) & $\begin{array}{l}0.022 \\
(0.032)\end{array}$ & $\begin{array}{l}0.041 \\
(0.046)\end{array}$ & $\begin{array}{l}0.094 * * \\
(0.043)\end{array}$ \\
\hline Cost (Norway, B) & $\begin{array}{l}0.112^{*} \\
(0.057)\end{array}$ & $\begin{array}{l}0.060 \\
(0.036)\end{array}$ & $\begin{array}{l}0.004 \\
(0.038)\end{array}$ \\
\hline
\end{tabular}

Note: The table reports results from robust OLS regressions of implemented inequality on a set of explanatory variables and interactions with subgroups of the population corresponding to regression equation (7). $\mathrm{B}$ is an indicator variable taking the value 1 if the spectator is conservative (column 1), has high education (column 2) or is a female (column 3). In these regression, we include all background variables used in Table 3, except the variable captured by B. All variables are defined as in Table 3 Standard errors in parentheses, $* p<0.1, * * p<0.05$, *** $p<0.01$ 